\title{
Recherches sur la morphogénèse des Filaires chez l'hôte intermédiaire
}

\author{
par O. BAIN (1) \\ Laboratoire de Zoologie (Vers) associé au C.N.R.S. ( $\mathrm{P}^{r}$ A.-G. ChaBaUd), \\ Muséum National d'Histoire Naturelle, 57, rue Cuvier, F. 75005 Paris, \\ Centre Muraz de Bobo-Dioulasso, Haute-Volta
}

\begin{abstract}
Résumé
Description complète ou fragmentaire de 4 cycles larvaires de Filaires vivipares (Dipetalonema viteae, D. dracunculoides, Wuchereria bancrofti, Onchocerca gutturosa) et de deux Spirurides (Spirura guyanensis, Draschia megastoma). Ces observations, jointes à nos précédentes études, permettent d'exposer les grandes lignes de l'organogénèse larvaire des Filaires chez leur hôte intermédiaire :
\end{abstract}

- Nous confirmons que la cellule $\mathrm{R}_{1}$, également présenté chez la microfilaire et chez la larve éclose du Spiruride, est l'initiale mésenchymateuse et que les cellules sous-cuticulaires de ces larves, bien que contractiles, sont ectodermiques.

- Le rectum est constitué par les cellules $R_{2}, R_{3}$ et $R_{4}$ (futures glandes rectales) et par un tube rectal de quelques cellules.

- Un organite binucléé, le prérectum, fait la jonction entre l'intestin et le rectum.

- Les initiales intestinales, généralement au nombre de cinq, apparaissent autour du corps interne de la microfilaire, qui est l'équivalent de la substance contenue dans le sac intestinal de la larve de Spiruride.

- La «capsule buccale» se constitue au début du deuxième stade larvaire ; elle comprend une invagination buccale et un tube cuticularisé, probablement sécrété par deux grosses cellules; ce tube est l'équivalent du pharynx des Spirurides.

- L'ébauche génitale est initialement ionstituée par quatre cellules; elles se divisent durant le deuxième stade.

(1) Ces recherches ont bénéficié du soutien financier de l'Organisation Mondiale de la Santé. 


\section{Summary}

Complete or fragmentary descriptions of 4 larval cycles from viviparous Filaria (Dipetalonema viteae, D. dracunculoides, Wuchereria bancrofti, Onchocerca gutturosa) and from 2 Spirurids (Spirura guyanensis, Draschia megastoma). These observations and others from previous work enable us to describe the main lines of the larval organogenesis of Filaria in their intermediate host.

- Confirmation is given that the $R_{1}$ cell, present in the microfilaria as well as in the Spirurid's hatched larva, is the initial of the mesenchyma, and that the subcuticular cells of these larvae, although contractile, are ectodermic.

- The rectum is formed by the cells $R_{2}, R_{3}, R_{4}$ (originating the rectal glands) and by the few cells of the rectal tube. rectum.

- The binucleate prerectum links the intestine with the

- The initials of the intestine (usually 5 cells) appear, around the internal body of the microfilaria, which is the equivalent of the substance contained in the intestinal bag of the Spirurid larva.

- The buccal capsule appears at the beginning of the 2nd larval stage; it is formed by a buccal invagination and a cuticularized tube, probably secreted by two large cells; this tube is comparable to the Spirurid's pharynx.

- The genital primordium is at first formed by 4 cells, which divide during the 2 nd stage.

\section{Sommaire}

\section{INTRODUCTION.}

I. Techniques D'Étude.

II. ETUdES DESCRIPTIVES.

Spirura guyanensis Ortlepp, 1924.

Draschia megastoma (Rud., 1819).

Dipetalonema viteae (Krepkogorskaya, 1933).

Dipetalonema dracunculoides (Cobbold, 1870).

Wuchereria bancrofti (Cobbold, 1877).

Onchocerca gutturosa Neumann, 1910.

Rectifications morphologiques: Foleyella candezei Fraipont, 1882 ; Onchocerca volvulus (Leuckart, 1893). 
III. ConClusions.

1) La microfilaire.

A. Anatomie d'une microfilaire.

B. Analogies entre l'anatomie d'une microfilaire et celle d'une larve de Filaire ovipare ou de Spiruride.

2) L'organogénèse.
A. Formation du rectum.
B. Le prérectum.
C. Formation de l'intestin.
D. Formation de l'œsophage.
E. Transformation de la région céphalique :

a) Morphogénèse du pharynx chez les Spirurides.

b) Morphogénèse de la capsule buccale chez les Filaires.

c) Homologie entre le pharynx des Spirurides et la capsule buccale des Filaires.

F. Formation de l'ébauche génitale.

G. Appareil excréteur.

H. Système nerveux et appareil sensoriel.

\section{INTRODUCTION.}

Dans cet article, nous nous proposons d'exposer les grandes lignes de l'organogenèse larvaire des Filaires chez leur hôte intermédiaire et d'en dégager la signification de la microfilaire.

Ces conclusions sont le résultat de l'étude de dix cycles de Filaires, que nous avons publiés précédemment (Bain, $1969 a, b, c$, 1970, $a, c$; Bain et Vassiliades, 1969) ou que nous décrivons ici; nous y ajoutons l'étude du cycle de deux Spirurides, qui a permis de clarifier certains points de la morphogenèse des Filaires.

Le plan que nous adoptons comprend : 1) un bref exposé des techniques d'étude; 2) la description, complète ou fragmentaire, de six cycles larvaires, suivie de quelques rectifications de la morphologie larvaire chez Foleyella candezei et Onchocerca volvulus, 3) les conclusions d'ensemble sur la morphogenèse des Filaires.

\section{I. - TECHNIQUES D'ETUDE.}

1) LES MICROFILAIRES.

Elles sont principalement étudiées à frais, à l'aide d'un colorant vital, l'Azur II dilué au $1 / 5000^{\circ}$ dans du Ringer; des gouttes épaisses sont également préparées et 
colorées au Giemsa. Les mesures de longueur et de largeur sont effectuées à frais sur des microfilaires immobilisées en extension par la chaleur; les autres mensurations sont faites sur les microfilaires colorées à l'Azur II.

\section{2) Les LARVes.}

Elles sont très fragiles et éclatent rapidement dans le Ringer. Nous avons donc utilisé un milieu complexe, dont la formule nous a été fournie par le professeur Vago (2) ; actuellement, nous avons remplacé ce milieu par du Ringer additionné de glucose $(4 \%)$; nous obtenons ainsi une survie suffisamment longue des larves pour pouvoir les observer en parfait état.

Les stades infestants sont mesurés après immobilisation en extension par la chaleur. Des vues apicales sont effectuées chez des stades II et des formes infestantes après fixation au formol à $7 \%$.

\section{II. - ETUDES DESCRIPTIVES.}

\section{Spirura guyanensis Ortlepp, 1924.}

Le cycle de Spirura guyanensis a été étudié dans notre laboratoire par Quentin (sous-presse). Nous avons suivi le début du développement de ce Spiruride afin de comparer son organogénèse avec celle d'une Filaire.

\section{Matériel.}

Un Caluromys philander (136 HA), provenant de la région de Cayenne en Guyane, meurt au laboratoire ; à l'autopsie de nombreux spécimens ở et $q$ de $S$. guyanensis sont recueillis dans l'œsophage.

Les œufs embryonnés des femelles sont récoltés pour infester par voie orale des Locusta migratoria. Les larves se développent dans la cavité générale des Criquets.

(2) Milieu Moustique - Fraction minérale:

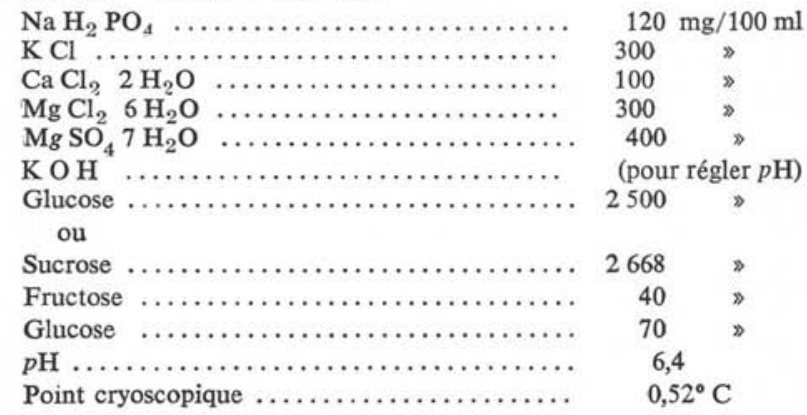




\section{Dimensions.}

Larve à l'éclosion : corps long de $280 \mu$ et large de $13 \mu$; râpe cuticulaire de $16 \mu$ de haut, pore excréteur à $105 \mu$ de l'apex; jonction œsophage-intestin à $150 \mu$ de l'apex; queue longue de $47 \mu$.

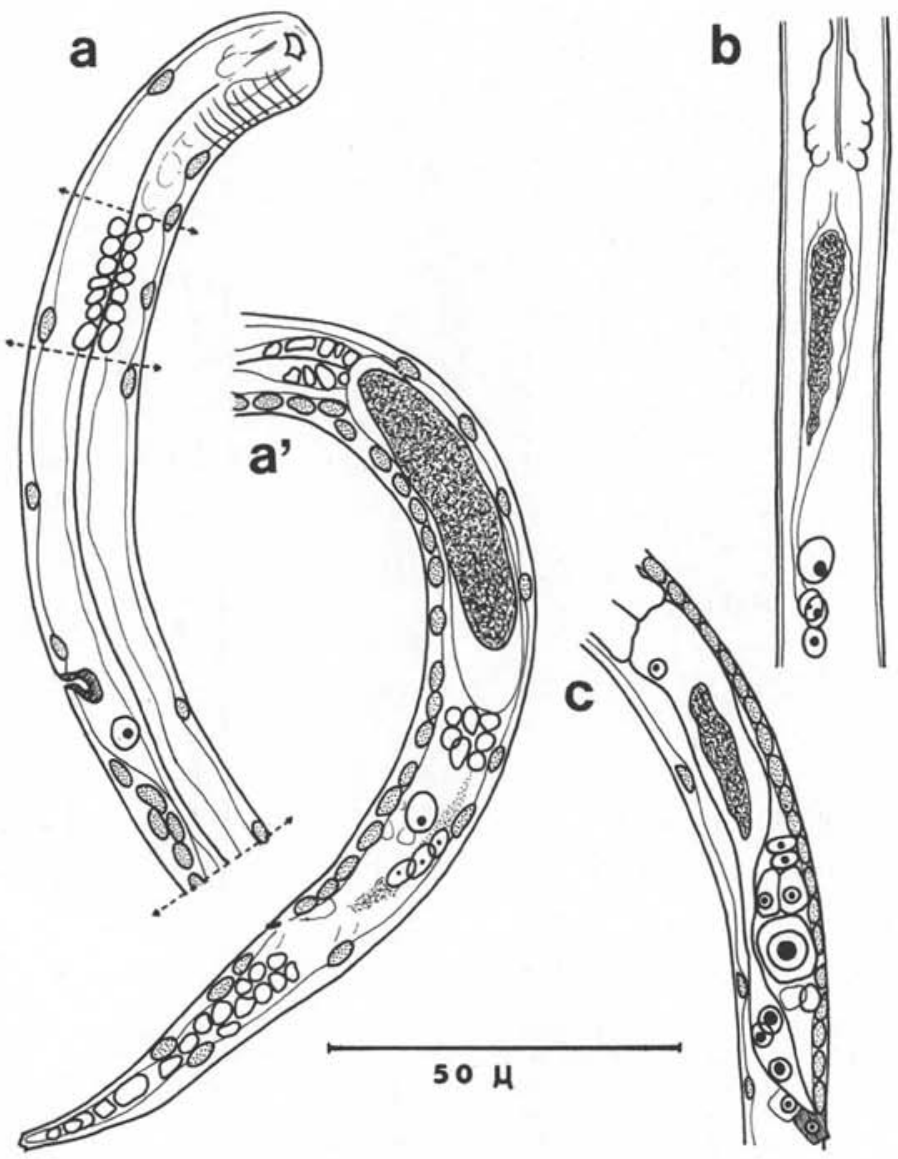

Fig. 1. - Spirura guyanensis. - $\mathrm{A}$ et $\mathrm{A}^{\prime}$ : larve à léclosion (dans la région antérieure, les noyaux ne sont pas tous représentés, sauf entre les 2 traits transversaux). - B et C: région moyenne de 2 larves de $48 \mathrm{~h}$, montrant l'évolution de l'intestin et des cellules $\mathbf{R}$, et l'emplacement des 4 initiales génitales

Larve de 5 jours: corps long de $380 \mu$ et large de $32 \mu$; anneau nerveux et pore excréteur respectivement à 93 et $110 \mu$ de l'apex; œsophage long de $177 \mu$; intestin long de $120 \mu$; queue longue de $49 \mu$. 


\section{Etude morphologique du début du développement larvaire.}

Les phénomènes les plus importants de la morphogénèse se déroulent dans la moitié postérieure de la larve; aussi ne représentons-nous généralement que cette région du corps sur les figures.

a

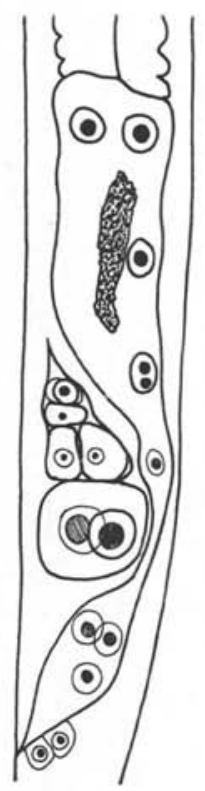

b

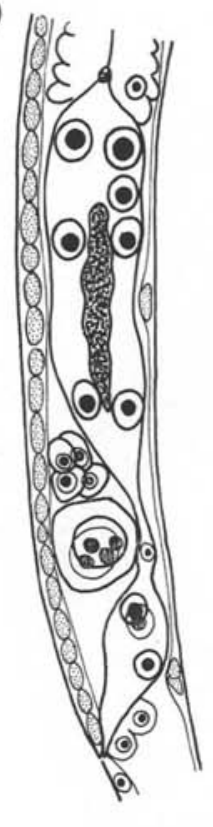

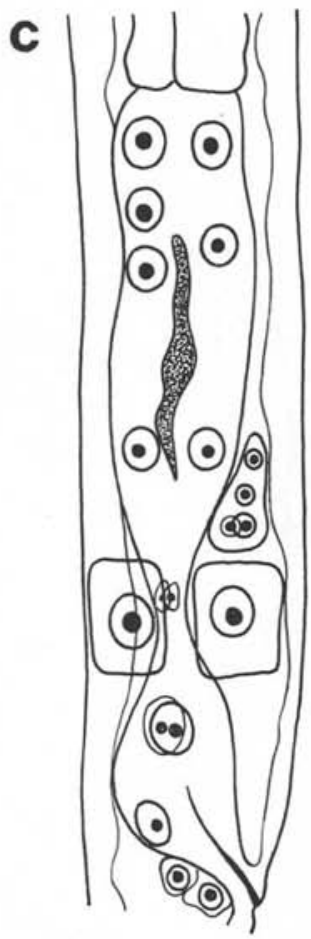

$50 \mu$

FIG. 2. - Spirura guyanensis. - A et B : larves âgées de 3 ou 4 jours : région moyenne du corps montrant les divisions de la cellule R1 (A: R1 $\times 2 ; \mathrm{B}: \mathrm{R} 1 \times 4$ ). $-\mathrm{C}$ : larve de 5 jours; les cellules filles de R1 ont migré à la périphérie du corps (2 sont représentées); les cordes ectodermiques ne sont pas figurées; l'ébauche génitale a une structure syncitiale

LARVe a L'Éclosion (fig. 1 A et A').

Elle est robuste; la tête porte une large pièce cuticularisée (crochet) sur le flanc gauche; une râpe formée par une dizaine de rangées transversales de pointes ornent l'apex; elle s'interrompt dans le plan du crochet (fig. $1 \mathrm{~A}$ ). La cuticule est doublée par une couche de noyaux ovoïdes, plus rapprochés sur la face ventrale. L'organisation interne est assez avancée : anneau nerveux visible ; pore excréteur très cuticularisé et 
noyau excréteur plus postérieur ; l'œsophage est constitué par des noyaux qui entourent l'axe œsophagien cuticulaire ; le groupe de noyaux le plus postérieur forme un bulbe ; la région antérieure de l'œsophage reste imprécise. En arrière de l'œsophage, la région centrale de la larve est occupée par une énorme masse anhyste réfringente, le corps interne, qui est enveloppé dans le sac intestinal à parois très minces. Entre cette masse et le pore anal s'étagent quatre noyaux rectaux vésiculeux à nucléole punctiforme : un gros noyau antérieur ventral $\left(R_{1}\right)$ et trois noyaux plus petits, dorsaux et postérieurs, disposés en file $\left(R_{2}, R_{3}, R_{4}\right)$; ces trois noyaux sont enveloppés dans une frange cytoplasmique qui les relie au pore anal. La queue est entièrement nucléée et porte trois pointes, dont une terminale.

\section{DÉVELOPPEMENT DU $1^{\text {er }}$ STADE PENDANT LES CINQ PREMIERS JOURS.}

Chez les larves de 48 heures, le corps interne s'amenuise tandis que la paroi du sac intestinal s'épaissit. Celui-ci est relié aux noyaux $R_{2}$ à $R_{4}$ par un cordon cytoplasmique très étroit, dorsal par rapport au noyau $\mathrm{R}_{1}$ (fig. $1 \mathrm{~b}$ ). Chez d'autres larves le rectum est clairement dessiné et contient les trois cellules $R_{2}$ à $R_{4}$. La cellule $R_{1}$ s'agrandit. Quatre autres cellules (deux petites antérieures et deux plus grosses postérieures) s'individualisent en avant de $R_{1}$ (fig. $1 c$ ) ; ce sont les initiales génitales.

Chez des larves obtenues le troisième et le quatrième jours, la paroi intestinale est épaisse ; ses noyaux sont bien visibles; certains sont en division; l'isthme qui relie l'intestin au rectum contient un ou deux noyaux qui constituent le prérectum. La cellule $R_{1}$ est très grande ; son noyau s'est divisé une première puis une deuxième fois, mais la division cytoplasmique ne s'est pas faite. En avant de $R_{1}$, les cellules génitales sont bien visibles (fig. $2 \mathrm{~A}$ et $\mathrm{B}$ ).

Chez des larves plus âgées ( $5^{\circ}$ jour) on retrouve quatre grosses cellules de même taille que $R_{1}$ qui sont disposées sous le tégument dans les quatre axes latéro-ventraux et latéro-dorsaux, c'est-à-dire dans les axes des futurs champs musculaires; des files longitudinales de petits noyaux sous-cuticulaires séparent ces quatre cellules et sont situées dans les axes latéraux, ventral et dorsal (fig. 2 C).

\section{Conclusion.}

Nous pouvons retenir de cette étude que l'organisation d'une larve de Spirura est identique à celle d'une microfilaire : on retrouve la cellule $R_{1}$, initiale du mésenchyme (Bain, $1970 b$ ), et les trois cellules rectales ; en outre, ce Spiruride démontre clairement que le corps interne est une volumineuse inclusion intestinale.

\section{Draschia megastoma (Rud., 1819).}

Le cycle de Draschia megastoma a été étudié par Roubaud et Descazeaux en 1921. Nous en avons repris l'étude pour préciser l'organogenèse larvaire de cet Habronematidae et la comparer à celle des Filaires. 


\section{Matériel.}

Draschia megastoma est recueilli dans l'estomac des chevaux, aux Abattoirs de Vaugirard (3).

Les $q$ sont disséquées; les œufs embryonnés libérés sont recueillis à l'aide d'un pinceau humecté d'urine de lapin ; le fond et les parois d'un petit bocal contenant des larves de Musca domestica sont badigeonnés d'œufs; l'humidité est maintenue par l'adjonction de gouttes d'urine de lapin.

\section{Allure du développement.}

Les larves se développent dans les tubes de Malpighi. A $25^{\circ}$, les mues I et II

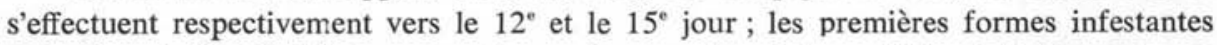
apparaissent dès le $15^{\mathrm{e}}$ jour. Les larves du premier stade se libèrent facilement ; au deuxième stade elles sont enroulées sur la face dorsale dans d'épaisses capsules ; les formes infestantes sont libres et mobiles.

\section{Croissance et dimensions.}

La larve épaissit rapidement, mais ne s'allonge presque pas jusquau $8^{\circ}$ jour ; elle est incurvée ventralement. La croissance en longueur est très importante au deuxième stade et pendant la maturation de la forme infestante.

Embryon : corps long de $112 \mu$ et large de $7 \mu$ (au niveau du pore excréteur) ; anneau nerveux, pore excréteur, cellule excrétrice et corps interne situés respectivement à $33 \mu, 47 \mu, 57 \mu$ et $80 \mu$ de l'extrémité antérieure ; queue longue de $15 \mu$.

Stade I: larve de huit jours : corps long de $155 \mu$ et large de $22 \mu$; anneau nerveux et pore excréteur respectivement à $42 \mu$ et $52 \mu$ de l'apex; œsophage large de $70 \mu$ débutant à $22 \mu$ de l'apex; intestin (+ caecum) long de $55 \mu$; queue longue de $22 \mu$.

Mue I: corps long de $315 \mu$ et large de $50 \mu$; anneau nerveux et pore excréteur respectivement à 48 et $70 \mu$ de l'apex; œsophage et intestin longs respectivement de $110 \mu$ et $130 \mu$; ébauche génitale à $180 \mu$ de l'apex; queue longue de $30 \mu$.

Mue II : larve de 14 jours au début de la mue II : corps long de $1.560 \mu$ et large de $90 \mu$; pharynx, œsophage musculaire et œsophage glandulaire longs respectivement de 18,95 et $145 \mu$; anneau nerveux et pore excréteur respectivement à 120 et $160 \mu$ de l'apex, rectum long de $80 \mu$, queue longue de $85 \mu$.

Forme infestante : chez un spécimen de $2.280 \mu$ de long et large de $80 \mu$, chambre buccale antérieure profonde de $8 \mu$, pharynx long de $65 \mu$, œsophage musculaire et œsophage glandulaire longs respectivement de 100 et $450 \mu$; anneau nerveux et pore excréteur situés respectivement à $155 \mu$ et $215 \mu$ de l'apex ; ébauche génitale à $390 \mu$ en avant de la jonction œsophage-intestin; queue longue de $105 \mu$. matériel.

(3) Nous exprimons notre vive reconnaissance à M. le Docteur Rigoulet qui nous a fourni le 


\section{Etude morphologique.}

\section{EMBRYON (fig. 3).}

Embryon trapu ; queue à extrémité obtuse entièrement nucléée ; armature céphalique comprenant sur le flanc gauche deux petites rangées symétriques de cinq rides cuticulaires (chaque ride descend obliquement vers les axes médians) et un crochet subterminal à base en trident, et sur le flanc droit une file latérale de trois pointes triangulaires ; quand le crochet est rétracté, son extrémité effilée vient s'intercaler entre

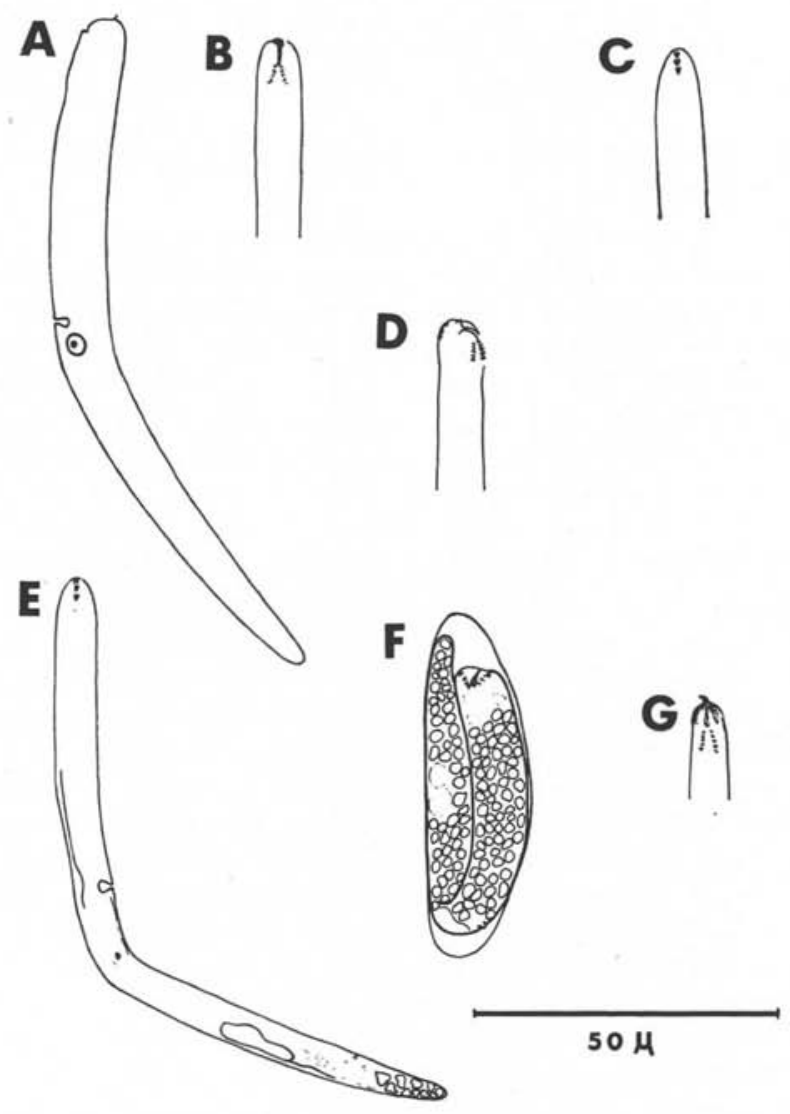

FIG. 3. - Draschia megastoma, œuf embryonné et larve à l'éclosion. - A : aspect sans coloration vitale. - B : région apicale, flanc gauche. - C : idem, flanc droit. - D : idem, vue médiane. - E: larve éclose, à l'Azur II. - F : œuf embryonné. - $\mathrm{G}$ : région céphalique montrant la base du crochet en trident 
les deux rangées de rides gauches, et les pointes triangulaires droites remontent au contact de sa base (fig. 3 B, C, D, G).

Aucune cellule ne se colore électivement à l'Azur II, mais ce colorant crée un fond uniforme qui facilite les observations: anneau nerveux parfois visible, pore excréteur et noyau excréteur reliés par une plage anucléée ventrale; pore anal souvent indiscernable ; une ou deux plages réfringentes (corps interne) situées à mi-distance entre le pore anal et le pore excréteur; colonne nucléaire plus épaisse dans la région antérieure; noyaux de la colonne assez anguleux.

Premier stade (fig. 4, 5, 6).

Ce stade comprend une longue phase de mise en place des principales ébauches des organes, qui dure neuf à dix jours, puis une courte phase de croissance.

$1^{\text {re }}$ phase: Les différentes étapes du développement se suivent aisément sur les figures que nous décrivons brièvement.

Du premier au cinquième jour les embryons ne changent guère de forme et le développement ne se manifeste que par l'apparition de structures nucléaires: développement de la cellule excrétrice et apparition des quatre noyaux rectaux en avant du pore anal: un gros noyau antérieur $\left(R_{1}\right)$, deux petits noyaux rapprochés gauche et droit $\left(R_{2}\right.$ et $\left.R_{3}\right)$ et un petit noyau situé dorsalement au pore anal $\left(R_{4}\right)$ (fig. $4 \mathrm{~A}$ ); les noyaux de la colonne nucléaire deviennent plus nets et parmi eux, quelques noyaux à nucléoles plus réfringents apparaissent en avant de $\mathrm{R}_{1}$ (fig. $4 \mathrm{~B}$ ) ; ceux-ci deviennent plus nombreux, et les plus antérieurs sont situés près de la pointe de la cellule excrétrice ; une zone réfringente anucléée en forme de $\mathrm{V}$ horizontal et dorsal, se dessine souvent à mi-distance entre $\mathrm{R}_{1}$ et la cellule excrétrice; un bouchon cuticulaire se forme en arrière du pore anal (fig. $4 \mathrm{C}$ ).

Ensuite, la larve épaissit fortement dans la région postérieure. Le noyau $R_{1}$ se divise en deux noyaux presque axiaux; $R_{2}$ à $R_{4}$ se regroupent en avant du bouchon anal; les noyaux situés en avant de $R_{1}$ deviennent volumineux ; plusieurs d'entre eux ont une position très dorsale; un axe cuticulaire apparaît dans la moitié antérieure du corps; il est dorsal par rapport à la cellule excrétrice et ventral par rapport aux gros noyaux; un massif de petits noyaux ventraux avoisine son extrémité distale; les noyaux tégumentaires commencent à être visibles même dans la région antérieure de la larve; ils sont fréquemment groupés par deux (fig. $4 \mathrm{D}$ ). Par la suite, les deux cellules filles de $R_{1}$ se divisent à nouveau et donnent deux noyaux latéro-ventraux et deux noyaux latéro-dorsaux, séparés par quatre files longitudinales de petits noyaux plus superficiels; le bouchon anal est entouré par une paroi épaisse, principalement constituée par $R_{2}$ et $R_{3}$, latéraux, et $R_{4}$, dorsal et un peu plus postérieur; les gros noyaux médio-dorsaux sont entourés par un cytoplasme piqueté qui remonte un peu en avant de l'extrémité postérieure de l'axe cuticulaire; la région ventrale est constituée par de nombreux petits noyaux serrés (fig. $4 \mathrm{E}$ ).

Le cinquième jour, la larve est presque organisée: les gros noyaux médio-dorsaux et leur cytoplasme granuleux forment un intestin plein d'une douzaine de cellules environ, avec une sorte de caecum dorsal; l'œsophage s'est formé autour de l'axe cuticulaire dans la région postérieure; il est à peine ébauché sur les vingt premiers $\mu$ en avant de l'anneau nerveux; il est uni à l'intestin par une ébauche valvulaire ventrale, de quatre (?) petits noyaux; un massif de quelques noyaux situés à mi-hauteur de l'intestin et ventralement 


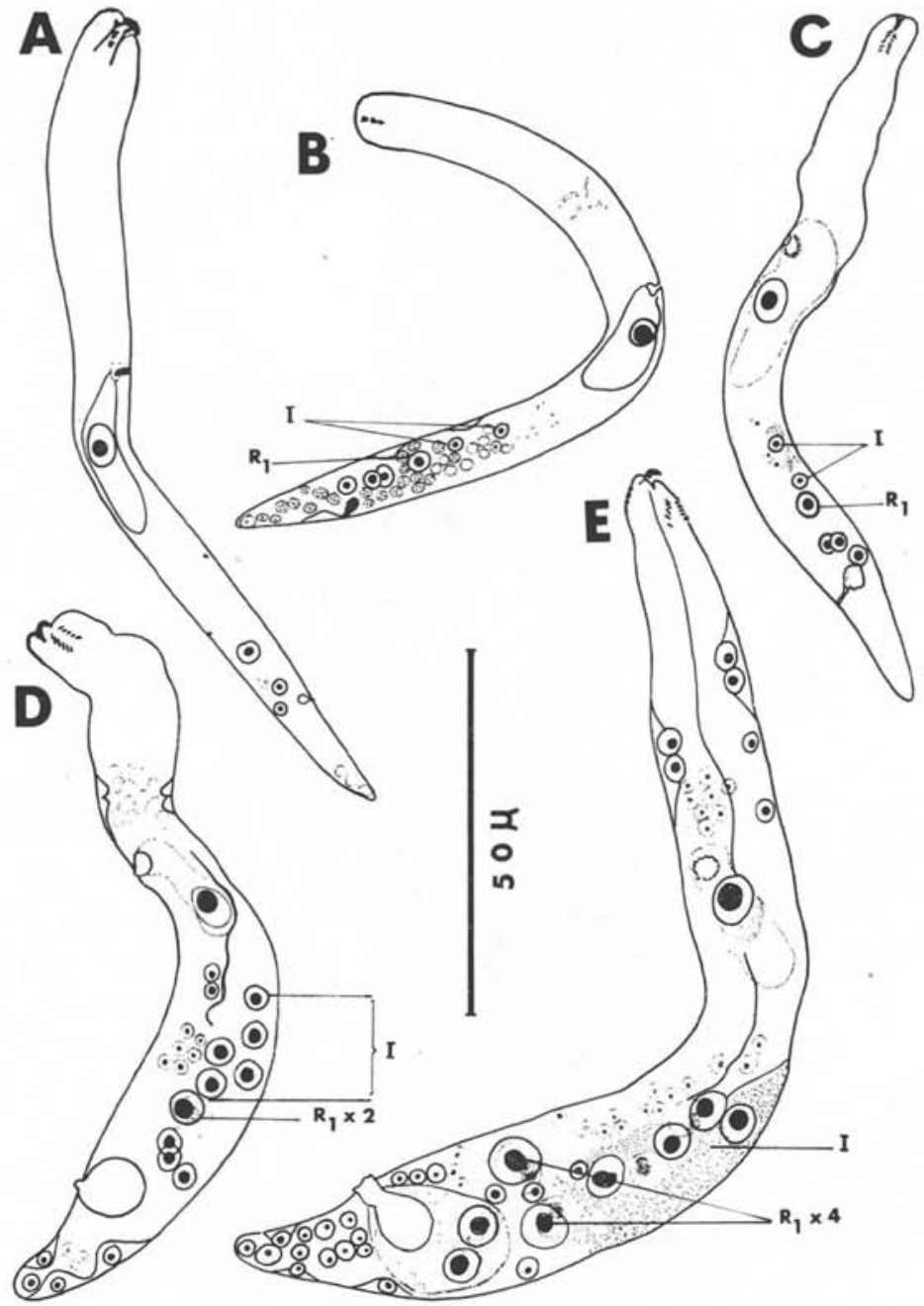

Fig. 4. - Drascha megastoma. - A : larve de 2 jours, apparition des noyaux R. - B et C: idem, mais les premiers noyaux sont visibles. - D : larve de 3 jours; R1 se divise une première fois. $-\mathrm{E}$ : larve de 4 jours; R1 a donné 4 cellules filles périphériques; la file de 3 noyaux située entre les 2 cellules filles du flanc droit représente la corde latérale ectodermique 
représente probablement l'ébauche génitale; les cellules ganglionnaires s'étendent de l'anneau nerveux à la cellule excrétrice; le bouchon anal est limité dans sa partie distale par les cellules $R_{2}$ à $R_{4}$ et entouré par un court tube cellulaire dans sa partie proximale (fig. $5 \mathrm{~A}$ ).

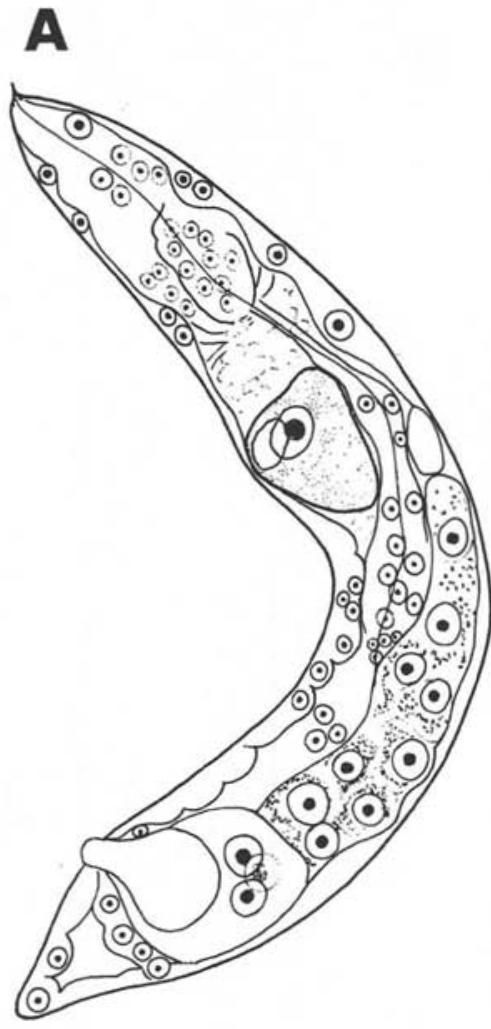

$50 \mu$

Fic. 5. - Draschia megastoma : larve de 5 jours

$2^{\circ}$ phase: Le rectum et l'intestin deviennent volumineux; l'œsophage est renflé à ses deux extrémités, riches en noyaux, qui sont reliées par une portion étroite pauvre en noyaux ; l'œsophage n'arrive pas jusqu'à l'apex (fig. $6 \mathrm{~A}$ ). Plus tard, un bourgeon œsophagien terminal s'organise autour de l'axe osophagien (fig. 6 B), qui se soudera finalement à l'œsophage préexistant. Durant cette période, l'ébauche valvulaire a fini par se confondre avec l'œsophage; le caecum intestinal a régressé; intestin et œsophage se sont placés 

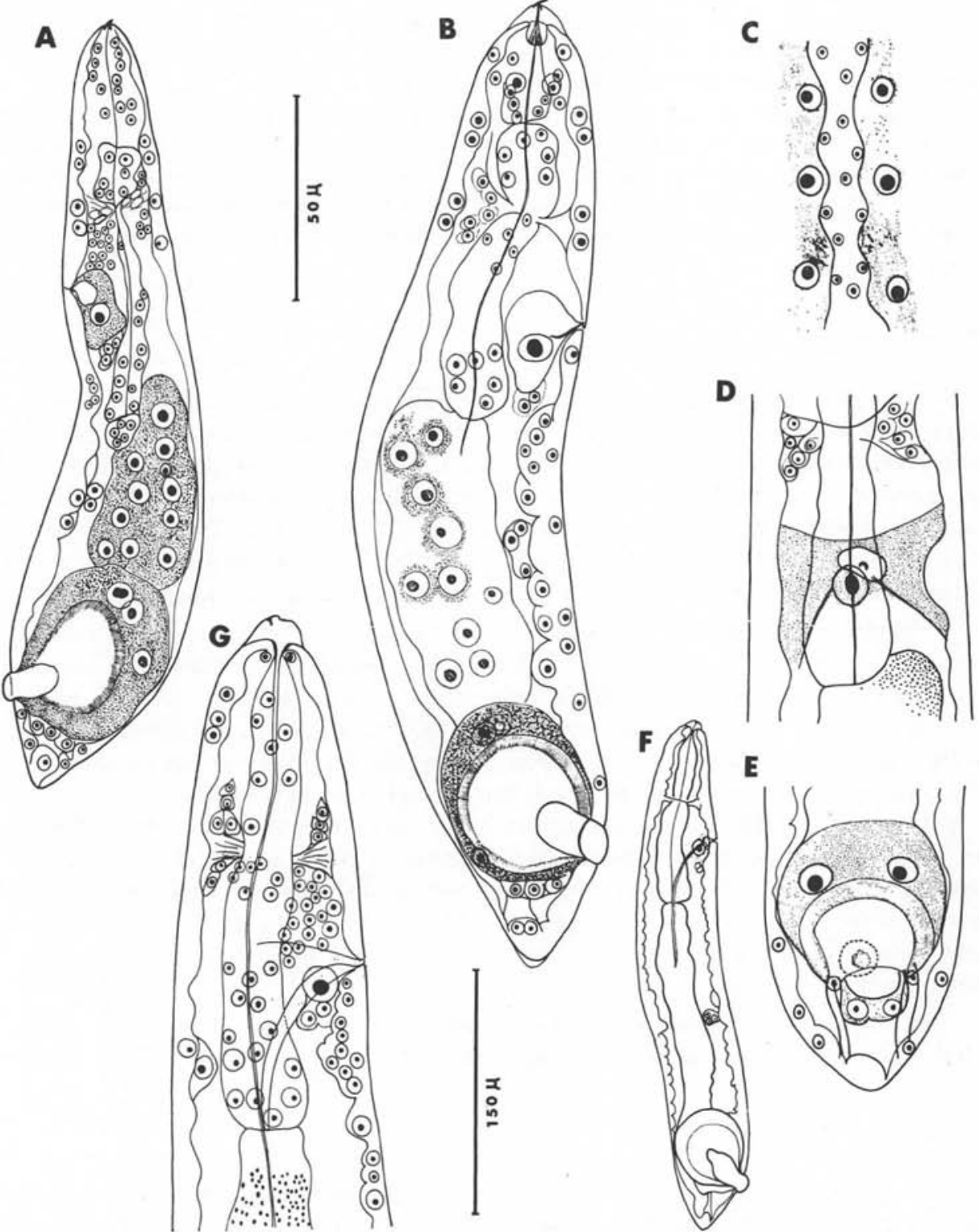

$\mathbf{E}$

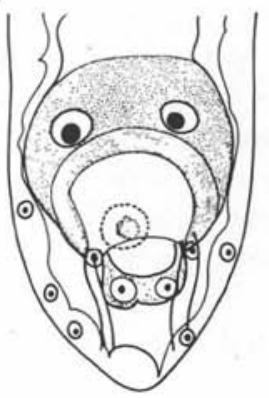

Fig. 6. - Draschia megastoma. - A: larve de 8 jours. - B: larve de 12 jours au début de la mue I. - C : idem, noyaux tégumentaires. $-\mathrm{D}$ : idem, région excrétrice en vue ventrale. $-\mathrm{E}$ : idem, région rectale en vue ventrale. - F et $\mathrm{G}$ : larve de 12 jours en mue $\mathrm{I}$ un peu plus avancée. G: détail de la région antérieure montrant l'invagination buccale 
dans le même axe médian. A ce stade la cuticule montre des stries transversales, interrompues au niveau des axes latéraux (fig. $7 \mathrm{H}$ ) et le tégument est formé par deux types de cellules: des cellules à noyaux très volumineux dans les axes submédians et trois files de petits noyaux dans les régions axiales (fig. $6 \mathrm{C}$ ).

Quand l'exuviation débute (fig. 6F), le dernier bourgeon œsophagien est encore distinct du reste de l'œsophage; quand la mue est plus avancée, l'œsophage arrive au contact d'une courte invagination cuticulaire buccale; deux gros noyaux, l'un ventral et l'autre dorsal, sont de part et d'autre de l'œsophage antérieur (fig. $6 \mathrm{G}$ ); le bouchon cuticulaire anal est décollé des trois grosses cellules rectales; la face interne de celles-ci a une large bordure striée (fig. $6 \mathrm{E}$ ).

\section{DeUXIÈME STADE (fig. 7).}

Les cellules intestinales et les cellules œsophagiennes situées en arrière de l'anneau nerveux se multiplient abondamment (fig. 7 B). L'œsophage comprend deux parties : une région antérieure mince, pauvre en noyaux (œsophage musculaire) et une région postérieure large, très longue et dense en noyaux (œsophage glandulaire) (fig. $7 \mathrm{I})$. A la fin du stade II, l'intestin se creuse d'arrière en avant ; le creusement s'accompagne de la formation de déchets souvent disposés en files plus ou moins spiralées ; les deux cellules prérectales ferment le passage entre le rectum et la lumière intestinale (fig. $I^{\prime}$ et $I^{\prime \prime}$ ).

En plus de ces modifications, il se forme en avant de l'œsophage un tube cuticulaire de section triangulaire qui se termine au contact de l'invagination buccale. Ce tube est très court et peu cuticularisé au début du stade II (fig. $7 \mathrm{~A}$ et $\mathrm{B}$ ), puis il s'allonge progressivement et forme le pharynx (fig. $7 \mathrm{E}$ et I). Chez les larves observées à frais, ce tube est bordé dans la région antérieure par des stries (ou des canalicules ?) qui partent de la profondeur des tissus adjacents et se terminent dans la lumière, à l'apex du pharynx (fig. $7 \mathrm{D}$ et $\mathrm{E}$ ). Chez les mêmes spécimens, après fixation au formol et éclaircissement au lactophénol, la paroi du pharynx paraît épaisse, mais de texture spongieuse (fig. $7 \mathrm{C}$ ). Le pharynx, quel que soit le stade de son développement est constamment bordé par deux très gros noyaux dorsal et ventral (fig. $7 \mathrm{~A}$ à $\mathrm{G}$ ). La bouche paraît légèrement ovalaire; en vue apicale quatre papilles sont discernables et deux amphides exiguës (fig. 7 F).

A la mue II, la communication entre l'intestin et le rectum est réalisée ; le bouchon anal et les déchets intestinaux sont expulsés.

\section{FORME INFESTANTE (fig. 8).}

La région céphalique se rétrécit à l'apex; la tête est légèrement bombée sous la poussée des papilles du cycle labial externe ; il n'y a pas de reliefs médians. La bouche est hexagonale, légèrement comprimée latéralement avec les angles dorsal et ventral arrondis ; il n'y a ni lèvres ni pseudolèvres; cycle labial interne de six papilles; cycle labial externe et cycle céphalique de quatre papilles chacun (fig. $8 \mathrm{C}$ ). La cavité buccale est courte, hexagonale, cuticularisée ; elle est limitée à sa base par quatre dents latéro- 


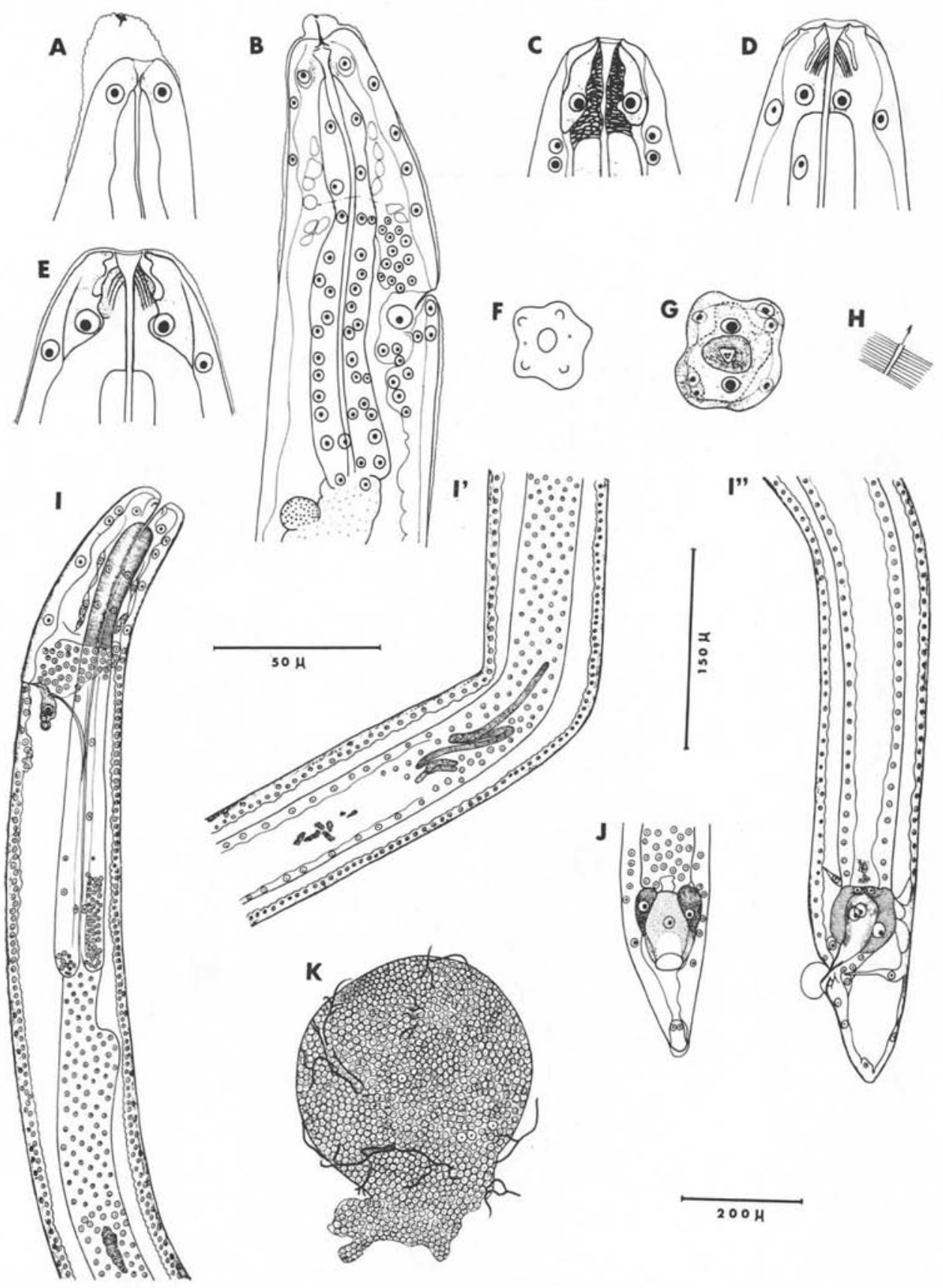

Fig. 7. - Draschia megastoma. - A et B, jeune $2^{e}$ stade : en A, début de la formation du pharynx, vue latérale; en B, multiplication des noyaux du futur œsophage glandulaire. - C: région pharyngienne d'un stade II fixé au formol, vue latérale. - D et E: région pharyngienne, à frais, respectivement en vue médiane et en vue latérale. - F : tête, en vue apicale d'un stade II. - G : coupe transversale optique de la région pharyngienne. - H: ornementation cuticulaire du stade I. I, I' et I": stade II en vue latérale. - J : région caudale du même stade en vue ventrale. K : capsule d'un stade II 

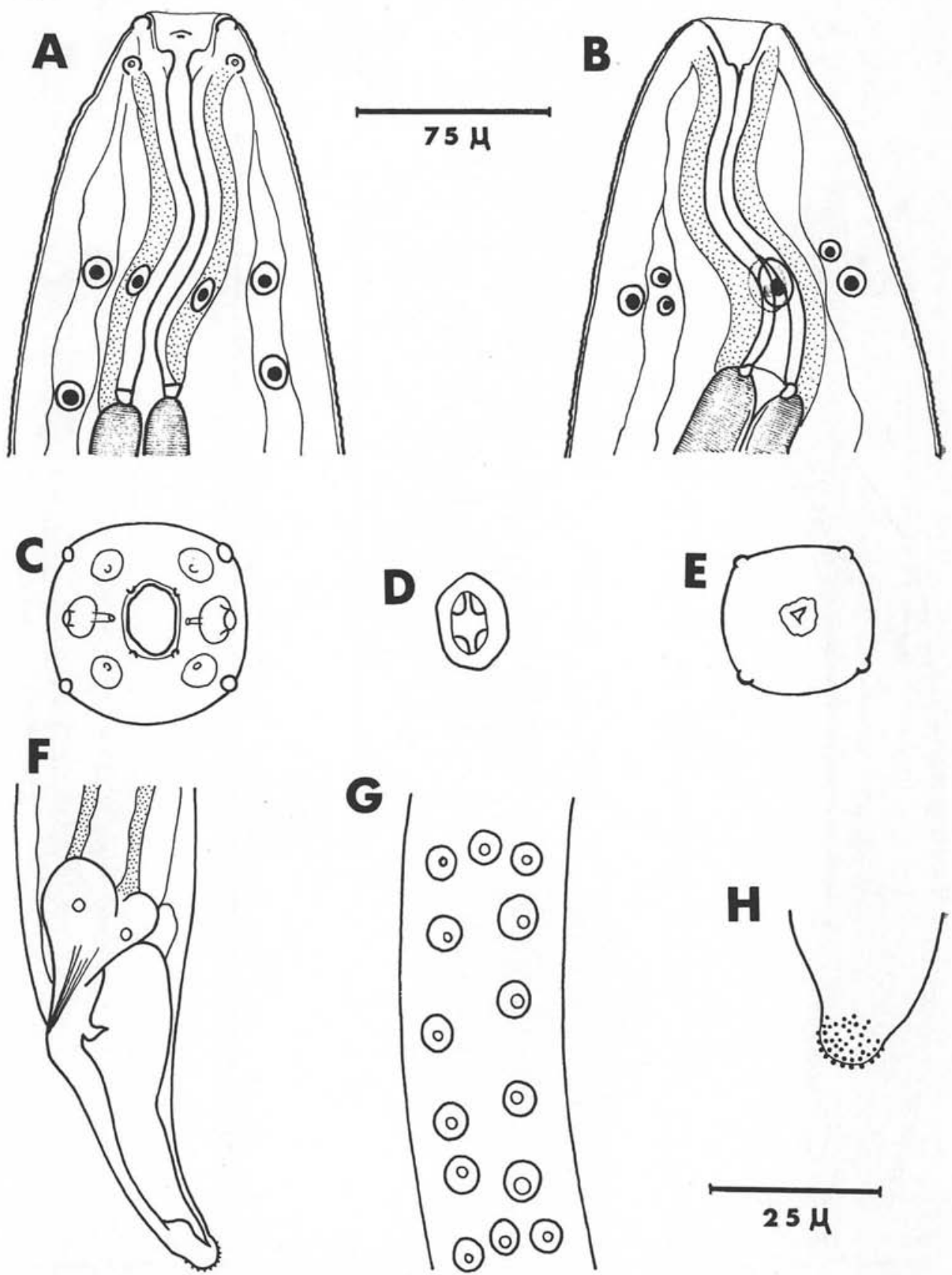

FIG. 8. - Draschia megastoma, stade infestant. - A : tête, vue latérale. - B : idem, vue médiane (les papilles ne sont pas représentées). - C: idem, vue apicale. - D: coupe transversale optique du pharynx au niveau des dents. - E: idem, coupe plus profonde. - F : région caudale, vue latérale. - G : corde latérale. - $\mathbf{H}$ : extrémité caudale 
dorsales et latéro-ventrales (fig. 8D). Le pharynx a une section triangulaire; il est allongé, bordé par deux noyaux, ventral et dorsal, qui sont inclus dans le tissu pharyngien; la base du pharynx est renforcée par un anneau cuticulaire (fig. $8 \mathrm{~A}, \mathrm{~B}, \mathrm{E}$ ). La cuticule du stade infestant est finement striée transversalement; corde latérale constituée, dans la région moyenne du corps, par trois rangées de noyaux; la file centrale a des noyaux très espacés (fig. $8 \mathrm{G}$ ) ; pas d'ailes latérales ; l'œsophage musculaire présente souvent une région antérieure un peu différente à paroi plus fortement cuticularisée ; l'intestin est vide, avec une paroi épaisse. La région caudale est recourbée vers la face dorsale; la queue se termine par un renflement sphérique, couvert de petites pointes (fig. $8 \mathrm{~F}$ et $\mathrm{H}$ ).

\section{Conclusion.}

Chez $D$. megastoma, l'évolution de la région céphalique est particulièrement nette : la zone buccale s'invagine à la mue I pour former une cavité buccale ; un segment cuticulaire, le pharynx, est mis en place au stade II entre cette cavité et l'œsophage. A la lumière de ces observations, il devient possible d'interpréter les structures préosophagiennes des larves des Filaires et d'homologuer leur «capsule buccale» au pharynx des Spirurides.

\section{Dipetalonema viteae (Krepkogorskaya, 1933).}

Le cycle de Dipetalonema viteae a été étudié par Chabaud en 1954. Cette Filaire de Rongeur est très facile à entretenir au laboratoire, mais son évolution morphologique durant le premier stade est restée longtemps mal connue, à cause de l'extrême minceur des larves, qui rend les observations très difficiles. Nous décrivons ici la morphologie de cette espèce, dont nous avons pu reprendre utilement l'étude, après avoir observé de nombreux cycles de Filaires.

\section{Matériel.}

D. viteae est une Filaire entretenue au laboratoire chez le Hamster (hôte définitif expérimental) et la Tique Ornithodoros tartakowskyi (hôte intermédiaire). Les Ornithodores s'infestent en se gorgeant sur un Hamster dont le sang est riche en microfilaires.

\section{Allure du développement.}

Les larves se développent dans les muscles (muscles dorso-ventraux et musculature du pharynx) ; elles peuvent exceptionnellement se développer dans les acini venimeux (Bain, 1967).

A $29^{\circ}$ les mues I et II s'effectuent respectivement le $11^{\circ}$ et le $18^{\circ}$ jour. Les premières formes infestantes apparaissent le $21^{\circ}$ jour. 


\section{Croissance et diménsions.}

La microfilaire ne grandit pratiquement pas, ni en largeur ni en longueur, pendant les huit premiers jours; un peu avant la première mue, la larve commence à s'allonger ; la croissance devient alors rapide.

Microfilaire : corps long de $247 \mu$ et large de $5 \mu$; anneau nerveux et pore excréteur situés respectivement à $48 \mu$ et $78 \mu$ de l'apex; noyau excréteur à $12 \mu$ du pore excréteur ; $R_{1}$ à $175 \mu$ de l'apex ; distances $R_{1}-R_{2}$ et $R_{2}-R_{4}$ respectivement de $12 \mu$ et $5 \mu ; R_{4}$ à $50 \mu$ de l'extrémité postérieure.

Stade I: larve de huit jours: corps long de $245 \mu$ et large de $10 \mu$; pore excréteur à $75 \mu$ de l'apex; rectum haut de $27 \mu$; queue longue de $50 \mu$.

Mue $I$ : corps long de $305 \mu$ et large de $20 \mu$; anneau nerveux et pore excréteur respectivement à $60 \mu$ et $85 \mu$ de l'apex; œsophage long de $120 \mu$; intestin de même longueur ; rectum haut de $36 \mu$; queue longue de $60 \mu$; ébauche génitale à $230 \mu$ de l'apex.

Stade II : larve de 15 jours : corps long de $700 \mu$ et large de $25 \mu$; pharynx haut de $7 \mu$; anneau nerveux et pore excréteur respectivement à $72 \mu$ et $110 \mu$ de l'apex ; œsophage long de $280 \mu$ (œsophage glandulaire long de $130 \mu$ ); queue longue de $45 \mu$; ébauche génitale longue de $32 \mu$.

Stade infestant (selon Chabaud, 1954) corps long de 1.300 à $1.600 \mu$; chez un spécimen long de $1.400 \mu$, largeur de $6 \mu$, anneau nerveux et pore excréteur respectivement à $52 \mu$ et $90 \mu$ de l'apex ; œsophage musculaire et glandulaire longs respectivement de $150 \mu$ et $470 \mu$; queue longue de $65 \mu$.

\section{Etude morphologique.}

La fin du deuxième stade larvaire et la forme infestante ont été bien décrites par Chabaud (1952) ; nous n'étudions ici que le début de la morphogenèse et nous précisons la structure céphalique de la forme infestante.

\section{Microfilaire (fig. 9 A).}

Corps très allongé, sans gaine. Tête ronde, munie d'un crochet puissant subterminal (latéral gauche ?) dont la pointe fine et longue est dirigée vers l'arrière du corps ; du côté opposé au crochet, il existe une crête qui porte quelques épines cuticulaires. La région apicale comprise entre ces deux pièces sclérifiées peut se rétracter et entraîne alors le crochet et la crête qui viennent au contact l'un de l'autre (fig. 9 B). Les fibrilles contractiles qui activent cette région forment deux courtes bandes longitudinales. La cuticule est épaisse. Les noyaux sous-cuticulaires sont triangulaires, épais, irrégulièrement colorés à l'Azur II. L'emplacement de l'anneau nerveux est marqué par une zone transversale sans noyau. Le noyau excréteur est nettement plus postérieur que le pore excréteur ; celui-ci est entouré d'une frange chromophile. Le noyau $\mathrm{R}_{1}$ est séparé du 
groupe $R_{2}$ et $R_{4}$. Le pore anal n'est pas visible. La queue est effilée et se termine par une pointe anucléée.

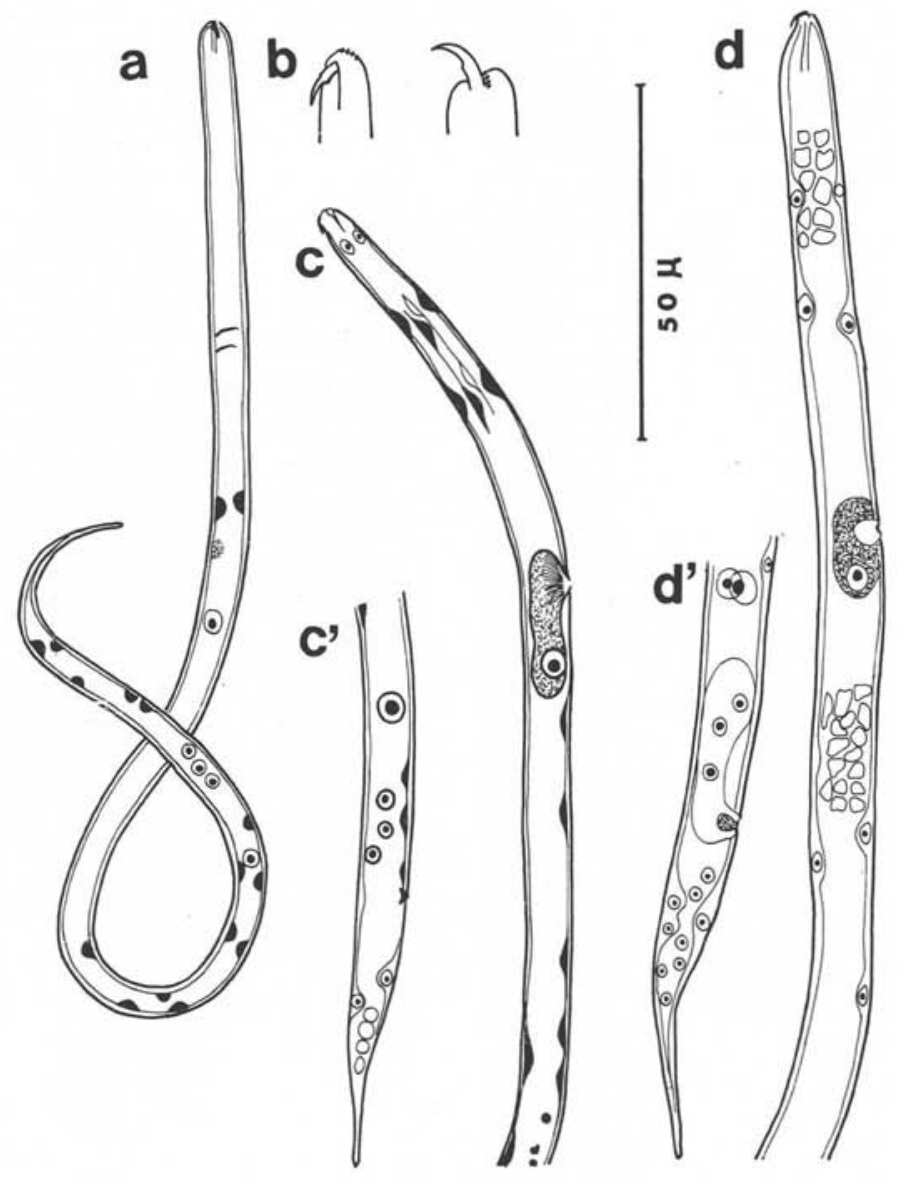

FIG. 9. - Dipetalonema viteae, microfilaire et larves en vue latérale. A : microfilaire. - B : région apicale de la microfilaire au repos et rétractée (à main levée). - C et C': larve de 6 jours. - D et D': larve de 7-8 jours, montrant la $1^{\text {re }}$ division de $R_{1}$ (les noyaux de la colonne nucléaire ne sont représentés que dans 3 régions)

\section{Premier STADE.}

La larve garde longtemps un aspect et une anatomie de microfilaire. Vers le sixième jour (fig. $9 \mathrm{C}$ et $\mathrm{C}^{\prime}$ ), les premières modifications apparaissent; les cellules sous-tégumentaires augmentent de taille (surtout dans la région postérieure), mais gar- 
dent leur forme triangulaire; elles paraissent être disposées en quatre files longitudinales : une dorsale, une ventrale et deux latérales; deux noyaux ovoïdes sont visibles au voisinage de la musculature céphalique. La cellule excrétrice est oblongue ; son cyto-

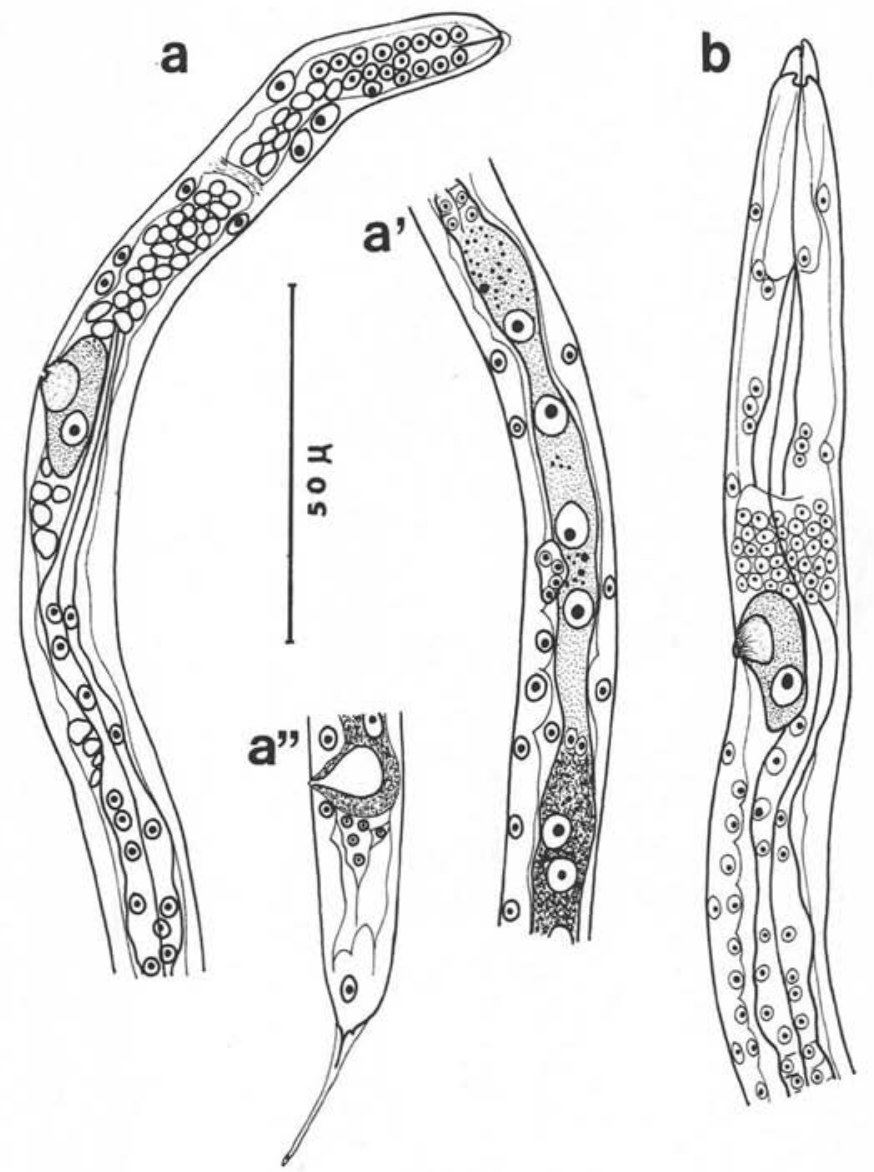

Fig. 10. - Dipetalonema viteae, larves de 10-11 jours en vue latérale. A et A": une larve au commencement de la mue I; la région antérieure de l'œsophage n'est pas encore organisée. - B : région antérieure d'une larve en mue I plus avancée

plasme apical a une structure radiée. Les noyaux de la colonne nucléaire s'arrondissent dans la région postérieure. Le noyau $R_{1}$ grossit ; les noyaux $R_{2}$ à $R_{4}$ sont toujours alignés. Le pore anal apparaît.

Aux $7^{e}-8^{e}$ jours (fig. $9 \mathrm{D}$ et $\mathrm{D}^{\prime}$ ), la cellule excrétrice s'arrondit. $\mathrm{R}_{1}$ se divise une fois. Les noyaux $R_{2}$ à $R_{4}$ sont enrobés dans la même masse cytoplasmique ; un petit bouchon 
cuticulaire anal apparaît. Dans la région moyenne de la larve, la minceur du corps rend difficile la discrimination entre les noyaux tégumentaires et ceux de la colonne nucléaire ; ils sont tous vésiculeux et à nucléole.

Les $10^{\circ}-11^{\circ}$ jours, l'organisation de la larve a beaucoup progressé (fig. 10). Le tégument semble être formé par deux couches épithéliales concentriques; dans la couche sous-cuticulaire, les noyaux sont espacés ; dans la couche interne, ils sont plus nombreux; les cellules de cette couche font saillie dans la lumière de la cavité générale de la larve (fig. 10 B). En arrière de la cellule excrétrice, l'appareil digestif est représenté par un cordon constitué par différentes régions ; l'œsophage a un segment antérieur très étroit, dorsal par rapport à la cellule excrétrice, et un segment postérieur plus large, riche en noyaux (fig. $10 \mathrm{~A}$ ) ; sa jonction avec l'intestin est assurée par un petit groupe de cellules chez lesquelles les limites cellulaires sont souvent visibles; l'intestin débute au niveau où se termine l'axe cuticulaire œsophagien ; il est formé par un étroit cordon de cytoplasme piqueté de granules, contenant peu de noyaux (4 ?) très volumineux et clairs (fig. $10 \mathrm{~A}^{\prime}$ ). Deux noyaux, plus petits forment la jonction entre l'intestin et le rectum. Celui-ci est très allongé ; son cytoplasme est grenu; les trois noyaux rectaux sont très nets; il existe deux noyaux antérieurs, l'un latéral gauche et l'autre latéral droit, et un noyau postérieur ; un groupe de petits noyaux est appendu à la paroi postérieure du rectum (fig. $10 \mathrm{~A}^{\prime \prime}$ ).

L'ébauche génitale est logée contre la paroi ventrale de l'intestin ; elle contient quatre noyaux (fig. $10 \mathrm{~A}^{\prime}$ ). A l'extrémité antérieure du corps, la cuticule se décolle légèrement ; à l'extrémité postérieure, le cytoplasme de la pointe caudale est dégénéré: la larve est en mue I. Chez des spécimens où l'exuvie I est un peu plus décollée, les deux angles de la base du crochet céphalique paraissent reliés à la pulpe du jeune stade II par deux fins ligaments (fig. $11 \mathrm{~A}$ ).

\section{DeUXième STADE.}

L'œsophage s'organise progressivement dans la région antérieure (fig. $11 \mathrm{~B}$ et $12 \mathrm{~A}$ ), mais il n'atteint jamais le pore buccal ; entre celui-ci et l'œsophage subsiste un segment cuticularisé court (fig. $11 \mathrm{~B}$ ), puis un tube très mince qui présente trois anneaux de cuticularisation (fig. $12 \mathrm{~A}$ ). La région œsophagienne qui s'étend jusqu'à la base de la cellule excrétrice est mince, avec des noyaux rares, tandis que la région postérieure est plus large et subit des multiplications nucléaires (fig. $11 \mathrm{~B}^{\prime}$ et $12 \mathrm{~A}^{\prime}$ ). Entre l'œsophage et l'intestin, une région rétrécie, à quelques noyaux, représente la valvule œsophagienne. L'intestin est un cordon plein ; les noyaux sont assez nombreux, plus petits qu'au stade I ; le cytoplasme renferme quelques granules (fig. $11 \mathrm{~B}^{\prime}$ ). Entre l'intestin et le rectum, deux petits noyaux (un dorsal et un ventral) constituent le prérectum, au cytoplasme grenu. Le rectum reste allongé, également à cytoplasme grenu, toujours avec trois noyaux. Quelques cellules forment un manchon autour de la partie distale du rectum; leur cytoplasme est en continuité avec celui des cellules sous-tégumentaires. Le bouchon anal n'a plus une structure homogìne : il comprend une frange très réfringente située au contact des trois cellules rectales et une zone distale moins brillante qui fait légèrement saillie à l'extérieur (fig. $11 \mathrm{~B}^{\prime \prime}$ ). L'ébauche génitale est au niveau de l'intestin, mais plus anté- 
rieure ; chez les jeunes stades II, elle est constituée par de nombreux noyaux (fig. $13 \mathrm{~A}^{\prime \prime}$ ). Vers le $15^{\circ}$ jour, la cuticule du stade II commence à se décoller dans la région caudale (fig. 12 B). Les cellules ganglionnaires appendues à l'anneau nerveux forment un massif
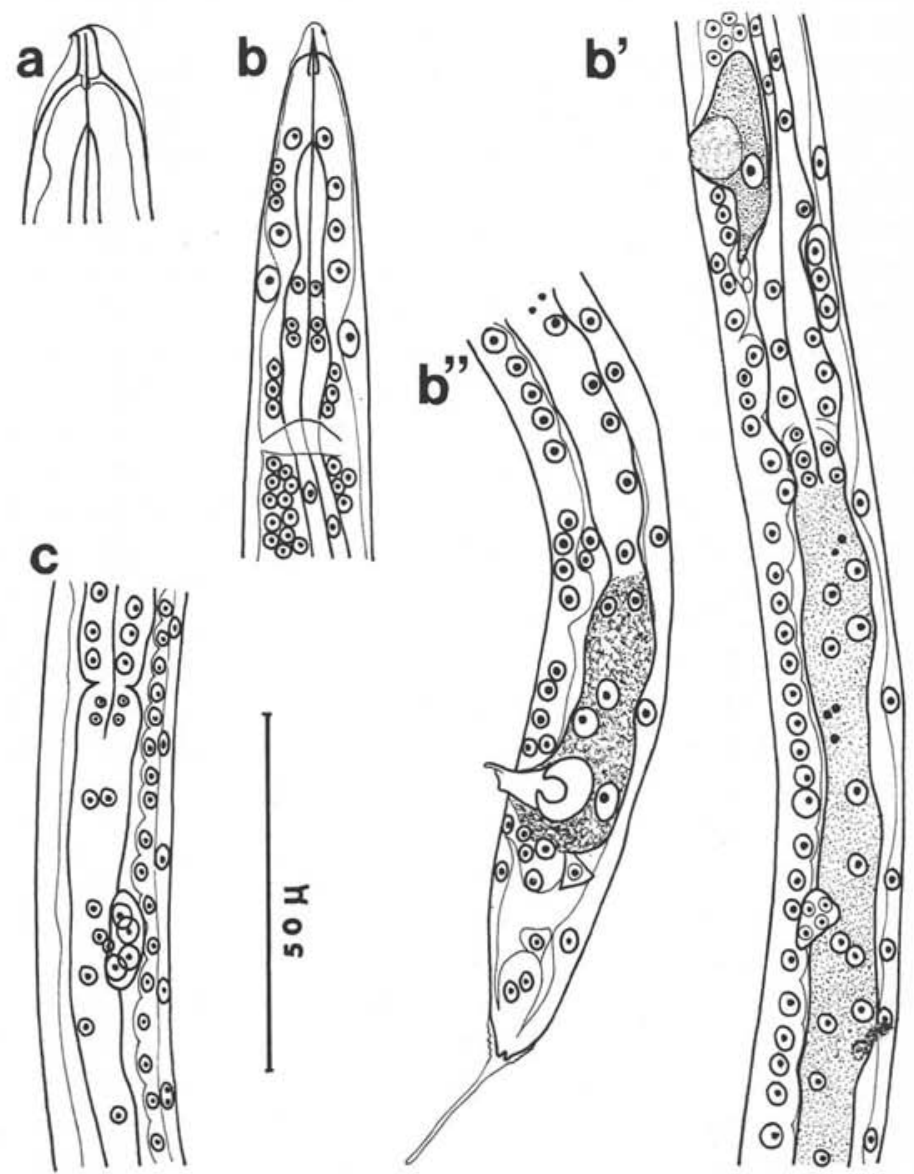

Fig. 11. - Dipetalonema viteae, larves en vue latérale. - A : détail de la région céphalique d'une larve en mue I. - B à B": un jeune stade II. - C : l'ébauche génitale, juste avant la phase de multiplication cellulaire

ventral et deux massifs latéraux plus courts (fig. $12 \mathrm{~A}$ ). La cellule excrétrice est très volumineuse. La portion antérieure de l'œsophage reste mince ; la portion postérieure présente une couche interne de gros noyaux espacés et une couche externe de nombreux petits noyaux (fig. $13 \mathrm{~A}^{\prime}$ ). L'intestin n'a pas de lumière ; ses noyaux sont disposés en deux files (fig. $13 \mathrm{~A}^{\prime \prime}$ ). Le prérectum n'est pas discernable. Le rectum comprend deux 
parties : les trois volumineuses cellules rectales et le manchon distal. Le bouchon anal est saillant; la frange réfringente en contact avec les trois cellules rectales est devenue denticulée.

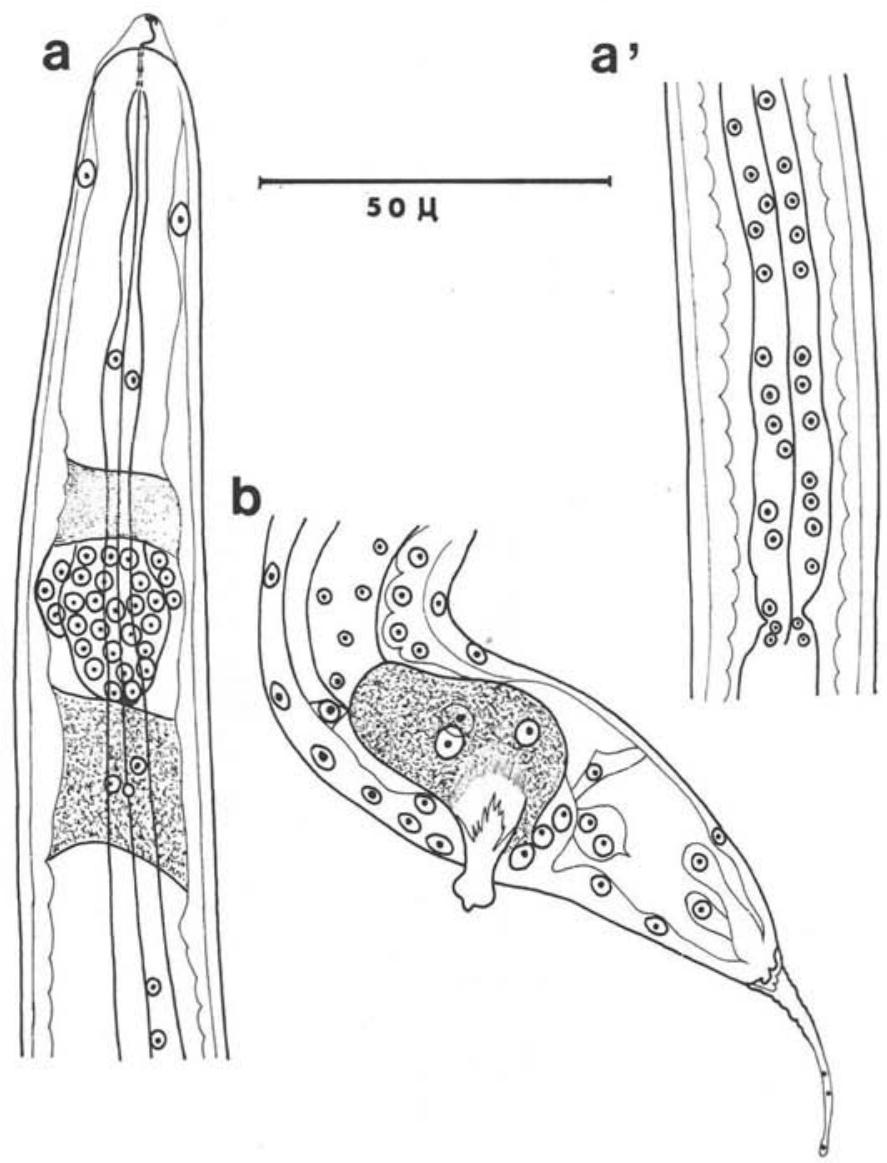

FIG. 12. - Dipetalonema viteae. - A et A' : un stade II de 14-15 jours, en vue ventrale, montrant les divisions nucléaires au niveau de l'œsophage postérieur. - B: région caudale d'une larve au début de la mue II, le $15^{\mathrm{e}}$ jour, en vue latérale

Vers le $18^{\circ}$ jour, les exuvies I et II sont expulsées.

\section{FORME INFESTANTE.}

Les structures nucléaires ne sont plus visibles sauf dans l'ébauche génitale. La tête est très petite ; elle porte deux cercles de quatre papilles chacun (seul le cercle céphalique a été observé en vue apicale) ; les amphides sont un peu en arrière du cycle labial 
externe. Le tube qui s'intercale entre la bouche et l'œsophage comprend une portion antérieure peu sclérifiée, aplatie latéralement, et une portion bien cuticularisée enchâssée dans l'œsophage, à section triangulaire (fig. $13 \mathrm{~B}, \mathrm{C}, \mathrm{D}$ ).

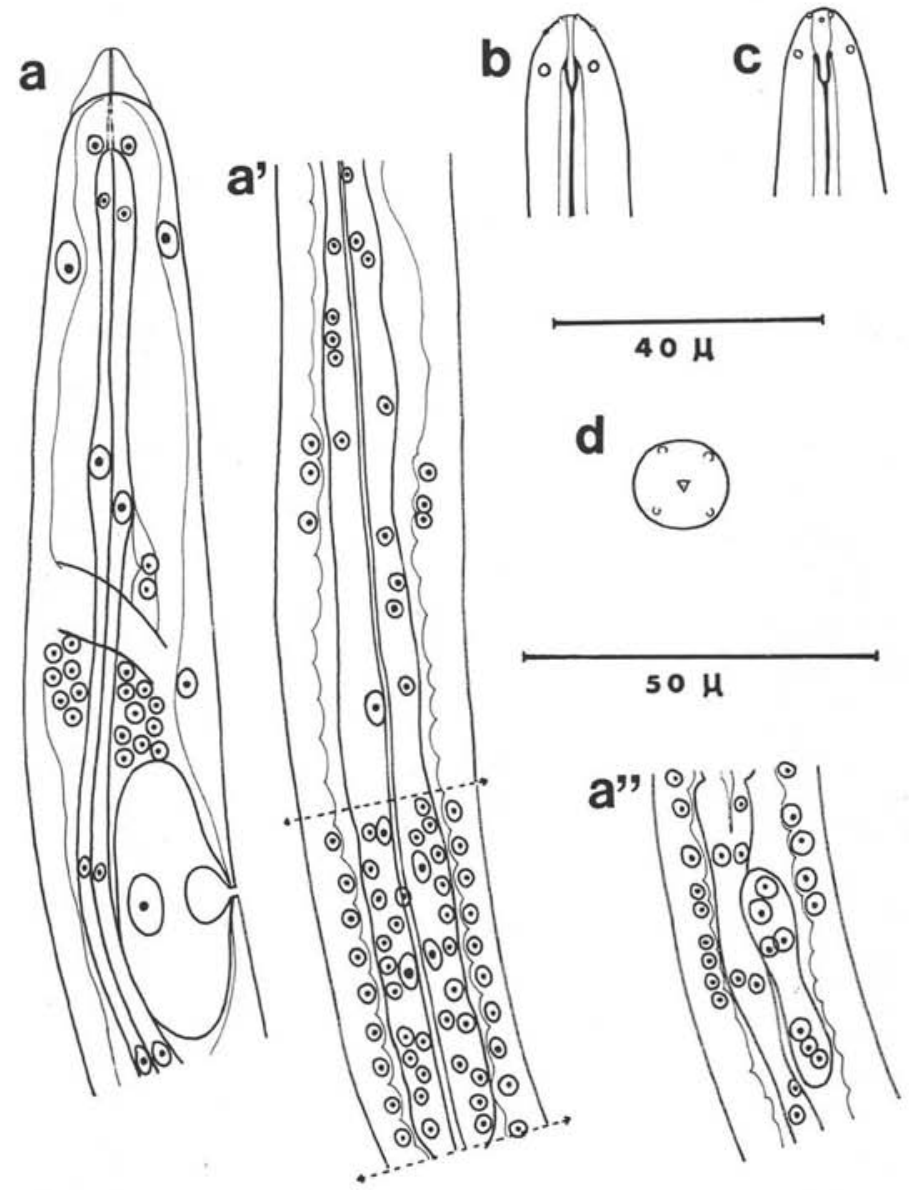

FIG. 13. - Dipetalonema viteae. - A, A' et A" : un stade II âgé en vue latérale (la structure de l'œsophage glandulaire est seulement représentée dans la région postérieure). - B à $\mathrm{D}$ : extrémité céphalique d'un stade infestant, successivement en vue médiane, latérale et apicale (A et A", éch. : $50 \mu$; B à D, éch. : $40 \mu$ )

\section{Conclusion.}

Nous avons voulu préciser chez $D$. viteae la morphogenèse de l'œsophage : le bourgeon œsophagien le plus antérieur est mis en place très tardivement, au moment de la mue I; la portion postérieure de l'œsophage, dont les noyaux se multiplient au cours 
du stade II, donne naissance à l'œsophage glandulaire ; il comprend un cortex riche en petits noyaux ronds (les noyaux glandulaires) et une étroite région axiale à noyaux espacés et ovoïdes (les noyaux œsophagiens, sensu stricto). En outre, l'ébauche génitale, dont les noyaux sont généralement très difficiles à dénombrer, contient clairement ici quatre noyaux, au stade I ; comme chez les Spiruridés, ces noyaux se multiplient au cours du stade II.

\section{Dipetalonema dracunculoides (Cobbold, 1870).}

Nelson, en 1963, a réussi au Kenya le cycle de D. dracunculoides chez Hippobosca longipennis et le décrit dans ses grandes lignes. Nous avons eu à notre disposition des stades infestants vivants (3) de cette espèce et nous en donnons une description plus détaillée.

\section{Matériel.}

Les stades infestants ont été récoltés chez des Rhipicephalus sanguineus $\$$, gorgés sur des chiens algériens infestés par $D$. dracunculoides (identification effectuée sur les adultes récoltés à l'autopsie des chiens).

\section{Dimensions.}

Forme infestante : corps long de $2350 \mu$ et large de $25 \mu$; pharynx haut de $7 \mu$; anneau nerveux et pore excréteur situés respectivement à $130 \mu$ et $185 \mu$ de l'apex ; œsophages musculaire et glandulaire longs respectivement de $220 \mu$ et $900 \mu$; rectum long de $32 \mu$; queue longue de $98 \mu$; ébauche génitale située soit à $100 \mu$ environ en arrière de la jonction œsophage musculaire-œsophage glandulaire, soit à une centaine de $\mu$ en arrière de la jonction œsophage-intestin.

\section{Etude morphologique de la forme infestante (fig. 14 et 15).}

La tête est arrondie; elle porte deux cercles de quatre papilles : un cercle labial externe très antérieur et un cercle céphalique plus postérieur. Les amphides sont à peu près à mi-hauteur entre ces deux cercles. La bouche est aplatie latéralement. Elle s'ouvre dans un tube, également aplati latéralement ; ce tube comporte une partie antérieure peu sclérifiée, et un court segment postérieur, très cuticularisé ; celui-ci est lui-même constitué d'un anneau large qui repose sur l'œsophage suivi d'un anneau étroit qui est enfoncé dans le tissu œsophagien (fig. 14). Les cellules ganglionnaires appendues à l'anneau nerveux forment deux petites masses ventrale et dorsale et deux masses latérales beaucoup plus longues. Le pore excréteur est exigu et communique avec la cellule excrétrice allongée par un conduit excréteur court. L'œsophage comprend deux portions

(4) M. Adadi nous a procuré des Tiques infestées et nous lui en sommes très reconnaissante. 

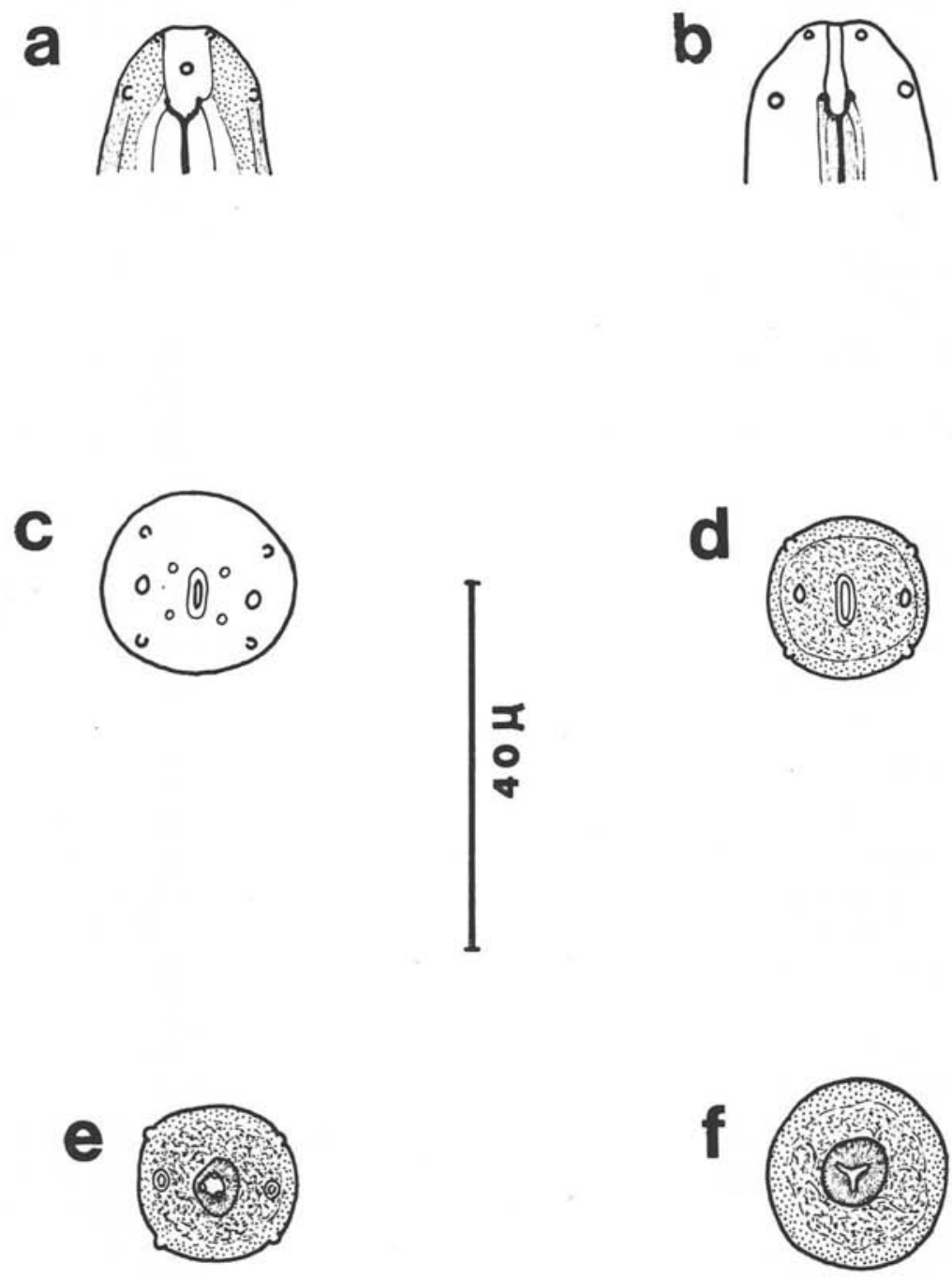

Fig. 14. - Dipetalonema dracunculoides; région céphalique de la forme infestante. - A : vue latérale. - B : vue médiane. - C : vue apicale. $-\mathrm{D}, \mathrm{F}$ et $\mathrm{E}$ : coupes optiques respectivement dans la région non cuticulaire du pharynx, au début de l'œsophage et dans l'œsophage musculaire 


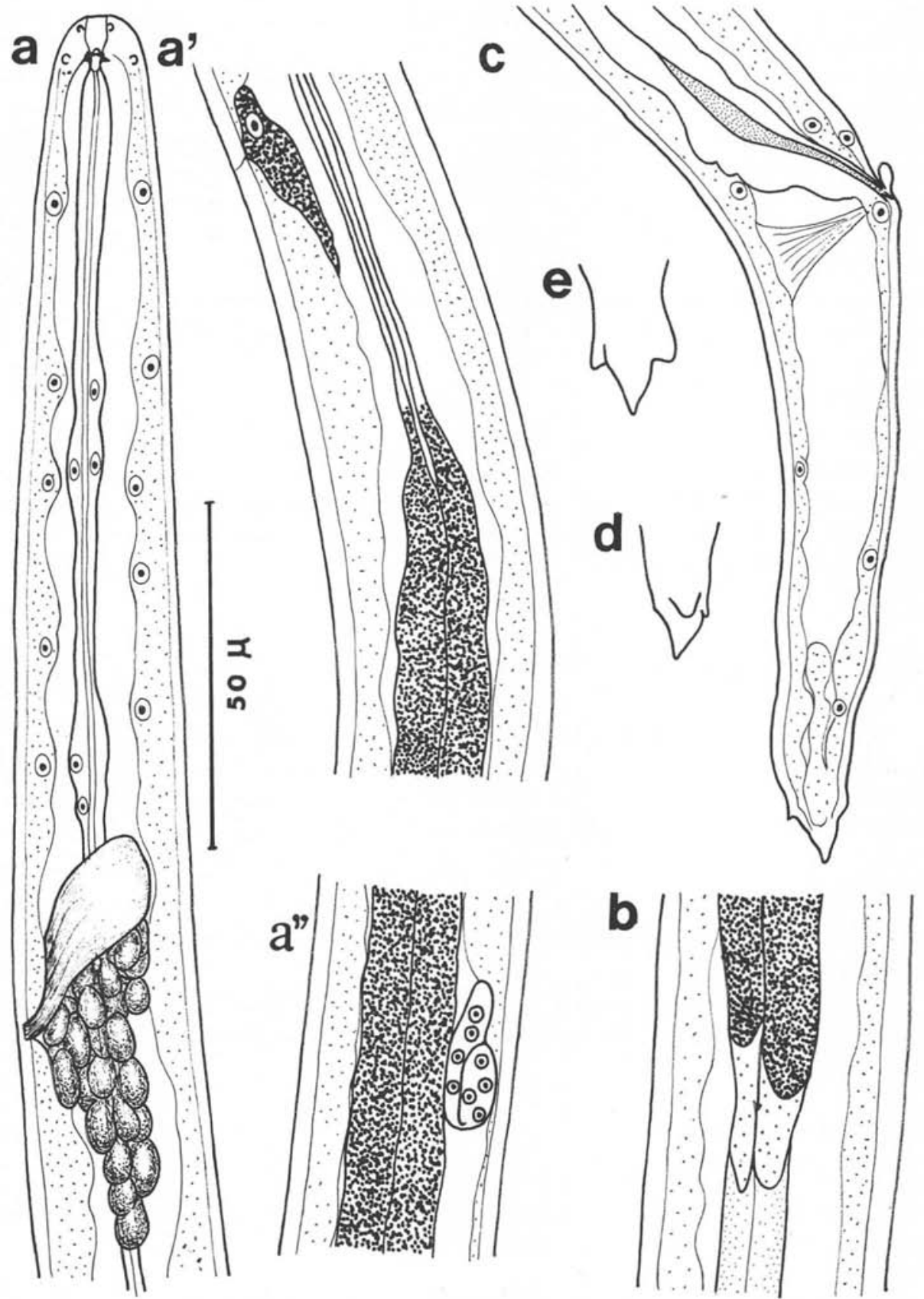

Fig. 15. - Dipetalonema dracunculoides, forme infestante. - $\mathrm{A}$ et $\mathrm{A}^{\prime}$ : région antérieure en vue latérale. - $\mathrm{A}^{\prime \prime}$ : ébauche génitale près de l'œesophage glandulaire chez une forme infestante ọ. - B : jonction csophage-intestin. - C : région caudale. - E et $\mathrm{D}$ : extrémité caudale, respectivement en vue médiane et latérale 
très distinctes : l'œsophage musculaire mince qui s'étend au-delà de la cellule excrétrice et l'œsophage glandulaire large, au cytoplasme granuleux (fig. $15 \mathrm{~A}$ et $\mathrm{A}^{\prime}$ ). L'intestin est creux mais ses deux parois épaisses sont appliquées l'une contre l'autre (fig. 15 B). Le rectum est allongé, un peu plus large à son apex que l'intestin ; sa lumière est fortement cuticularisée ; il n'y a pas de bouchon anal. La lèvre postérieure de l'anus peut être saillante. La musculature anale est mise en place (fig. $15 \mathrm{C}$ ). La queue est allongée; son extrémité est complexe : il existe un gros lobe terminal pointu et deux lobes latéraux ; la base du lobe terminal est soulignée par deux petites pointes ventrale et dorsale (fig. $15 \mathrm{D}$ et $\mathrm{E})$.

L'ébauche génitale est plurinucléée et ventrale ; elle est située soit près de la région antérieure de l'œsophage glandulaire $q$ (fig. $15 \mathrm{~A}^{\prime \prime}$ ), soit près de l'intestin ơ.

\section{Conclusion.}

La morphologie de la région céphalique de $D$. dracunculoides peut être prise comme type pour les Filaires: la tête est ornée par deux cercles de quatre papilles chacun (quatre papilles labiales externes, quatre papilles céphaliques plus postérieures) et deux amphides ; à la bouche fait suite un pharynx aplati latéralement, qui n'est fortement cuticularisé qu'à sa base.

\section{Wuchereria bancrofti (Cobbold, 1877).}

La morphologie larvaire de $W$. bancrofti a été étudiée avec soin par Abe en 1937 puis par Kobayashi en 1940 ; nous reprenons toutefois l'étude de ce matériel, car les hypothèses de ces auteurs sur l'origine de certains organes de la larve diffèrent de ce que nous avons observé régulièrement chez d'autres espèces.

\section{Matériel (5).}

Le porteur de microfilaires de $W$. bancrofti est originaire de Koupela, situé au nord de la Haute-Volta.

Le vecteur, Anopheles gambiae A, est une souche de Tonogosso (Haute-Volta) qui est entretenue à la Section Entomologique du Centre Muraz (Bobo-Dioulasso, HauteVolta).

\section{Allure du développement.}

La larve se développe dans les muscles thoraciques.

A $26^{\circ}-28^{\circ}$, les mues I et II s'effectuent respectivement le $5^{\circ}$ jour et le $10^{\circ}$ jour. Les premières formes infestantes apparaissent le $11^{\circ}$ jour.

(5) Cette étude a été effectuée au laboratoire d'Entomologie (O.R.S.T.O.M.) du Centre Muraz, grâce à l'aide de $\mathrm{M}$. Brengues, que nous remercions très amicalement. 


\section{Croissance et dimensions.}

La larve s'épaissit et atteint sa plus petite longueur vers la $70^{\circ}$ heure. A la mue $\mathbf{I}$, elle a la longueur de la microfilaire. Ensuite, la croissance est importante.

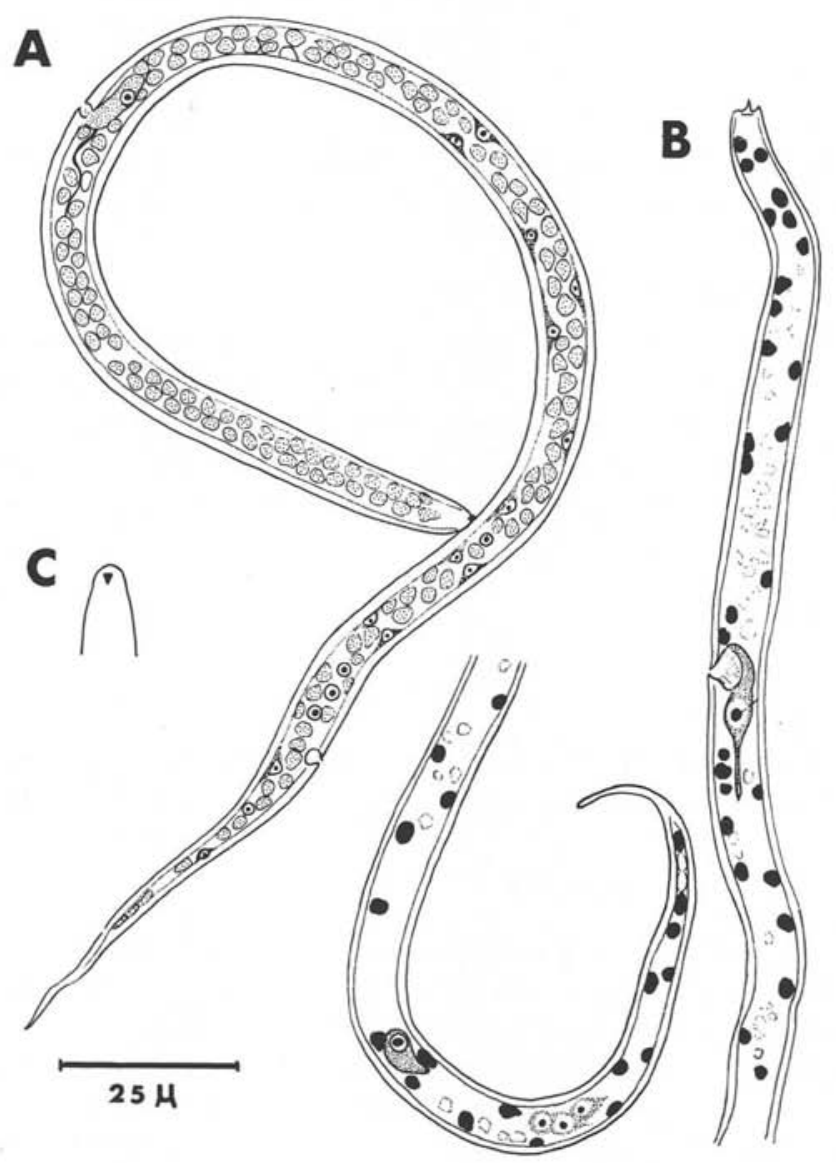

Fig. 16. - Wuchereria bancrofti. - A : microfilaire. - B : larve de 40 heures. - C: crochet de la microfilaire, vue de face

\section{Microfilaire.}

Larve âgée de $15 \mathrm{~h}$ : corps long de $316 \mu$, large de $8 \mu$; espace céphalique haut de $6 \mu$; anneau nerveux, pore excréteur et noyau excréteur respectivement à $58 \mu, 90 \mu$ et $97 \mu$ de l'apex ; $R_{1}$ à $218 \mu$ de l'apex ; distance $R_{1}-R_{2}$ et $R_{1}-R_{4}$ respectivement égales à $27 \mu$ et $37 \mu$; queue longue de $55 \mu$. 
Stade I : larve de $70 \mathrm{~h}$ : corps long de $168 \mu$ et large de $18 \mu$; pore excréteur, début de l'ébauche intestinale, $R_{1} \times 2$ situés respectivement à $50 \mu, 90 \mu$ et $110 \mu$ de l'apex ; ébauche intestinale haute de $12 \mu$; queue longue de $38 \mu$ et pointe caudale de $22 \mu$.

Mue I : corps long de $265 \mu$ et large de $36 \mu$; anneau nerveux et pore excréteur respectivement à $50 \mu$ et $65 \mu$ de l'apex ; œsophage, intestin et rectum longs respectivement de $92 \mu, 65 \mu$ et $45 \mu$; queue et pointe caudale longues respectivement de $53 \mu$ et de $22 \mu$; ébauche génitale à $140 \mu$ de l'apex.

Stade II : larve de huit jours : corps long de $515 \mu$, large de $35 \mu$; pharynx haut de $6 \mu$; anneau nerveux et pore excréteur respectivement à $82 \mu$ et $118 \mu$ de l'apex ; œsophage, intestin et rectum longs respectivement de $160 \mu, 180 \mu$ et $50 \mu$; queue longue de $46 \mu$.

Mue II : corps long de $1250 \mu$ et large de $45 \mu$.

Forme infestante : longueur du corps allant de $1500 \mu$ à $1620 \mu$ avec longueur de l'œsophage variant de $510 \mu$ à $580 \mu$. Chez le spézimen figuré, corps long de $1620 \mu$, large de $30 \mu$; pharynx haut de $10 \mu$; anneau nerveux et pore excréteur respectivement à $118 \mu$ et $160 \mu$ de l'apex; œsophage long de $580 \mu$ (œsophage musculaire long de $190 \mu$ ) ; masse ganglionnaire haute de $42 \mu$; rectum long de $95 \mu$, queue longue de $65 \mu$.

\section{Etude morphologique.}

\section{Microfil aire.}

Elle a été très bien étudiée par Rodenwalt (1908 et 1909) et par Fülleborn (1913). Nous représentons (fig. $16 \mathrm{~A}$ et $\mathrm{C}$ ) une de celles que nous avons observées.

Premier Stade (fig. $16,17,18$ et 19).

Jusqu'à la $40^{\circ}$ heure, la larve est encore très proche de la microfilaire (fig. $16 \mathrm{~B}$ et 17 A). Les premières modifications s'observent chez les larves de 60 heures (fig. 17 B) : les noyaux sous-cuticulaires sont plus gros; la cellule excrétrice est volumineuse ; un axe cuticulaire médian s'étend du voisinage de la cellule excrétrice jusqu'à mi-hauteur du corps ; chez certaines larves un massif cytoplasmique granuleux, renfermant quelques noyaux ronds et à nucléole, se dessine en arrière de cet axe ; la cellule $R_{1}$ a un cytoplasme bien individualisé et son noyau est très gros; les noyaux $R_{2}, R_{3}$ et $R_{4}$ forment le rectum ; les limites cellulaires sont visibles, le bouchon cuticulaire anal est petit.

Chez la larve de 70 heures (fig. $18 \mathrm{~A}$ ), les noyaux sous-cuticulaires sont ronds et avec nucléole. La cellule $R_{1}$ se divise une fois ; le rectum est parfois prolongé à son apex par une bande cytoplasmique verticale (fig. $18 \mathrm{~B}$ ). Chez des spécimens plus avancés, les deux cellules filles de $R_{1}$ se divisent à nouveau ; les quatre cellules filles sont situées dans le même plan transversal ; deux sont latéro-ventrales et deux sont latéro-dorsales. En avant des cellules $\mathrm{R}_{1}$, le massif cytoplasmique submédian se développe ; ses noyaux sont devenus assez gros pour être dénombrés : il en existe 5 (fig. 18 B et C). 
Chez une larve de quatre jours (fig. $18 \mathrm{D}$ ), la région antérieure à la cellule excrétrice n'est pas organisée ; mais en arrière, l'appareil digestif est représenté par un cordon plein qui comprend trois régions : l'œsophage muni d'un axe cuticulaire, contenant des

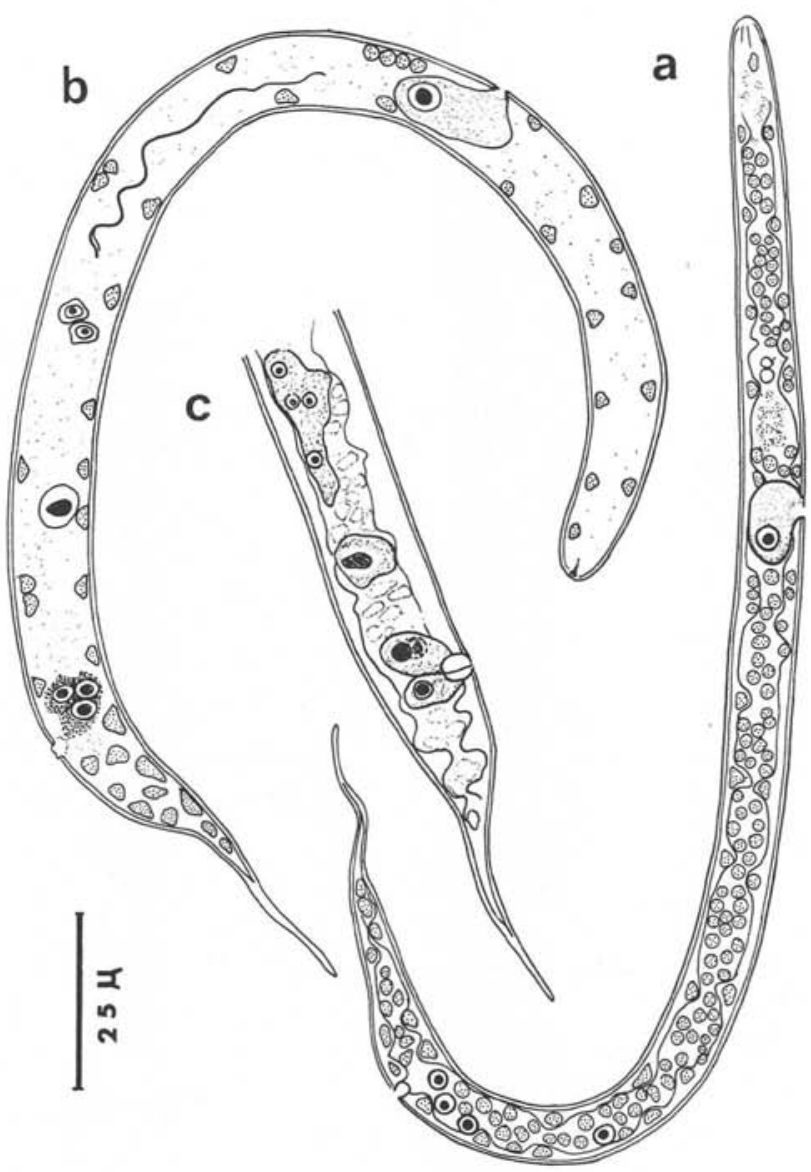

Fig. 17. - Wuchereria bancrofti, larves en vue latérale. - A : larve de $40 \mathrm{~h}$. - B : larve de $60 \mathrm{~h}$. - C : région postérieure d'une larve de $60 \mathrm{~h}$ plus évoluée

noyaux assez nombreux, répartis irrégulièrement ; une zone étroite, à quatre noyaux environ, fait la jonction entre l'œsophage et l'intestin ; l'intestin a un cytoplasme granuleux et renferme cinq noyaux; la jonction entre l'intestin et le rectum est marquée par deux noyaux plus petits ; le rectum est essentiellement constitué par un massif à 
trois noyaux; sa face postérieure est doublée par une couche de quelques cellules ; le bouchon cuticulaire n'est pas saillant ; vu de face, il présente trois cloisons incomplètes (une dorsale et deux latéro-ventrales) (fig. $18 \mathrm{E}$ ). Le tégument est très épais sous la cellule excrétrice. Quelques grosses cellules s'observent près de la face ventrale de l'intestin.
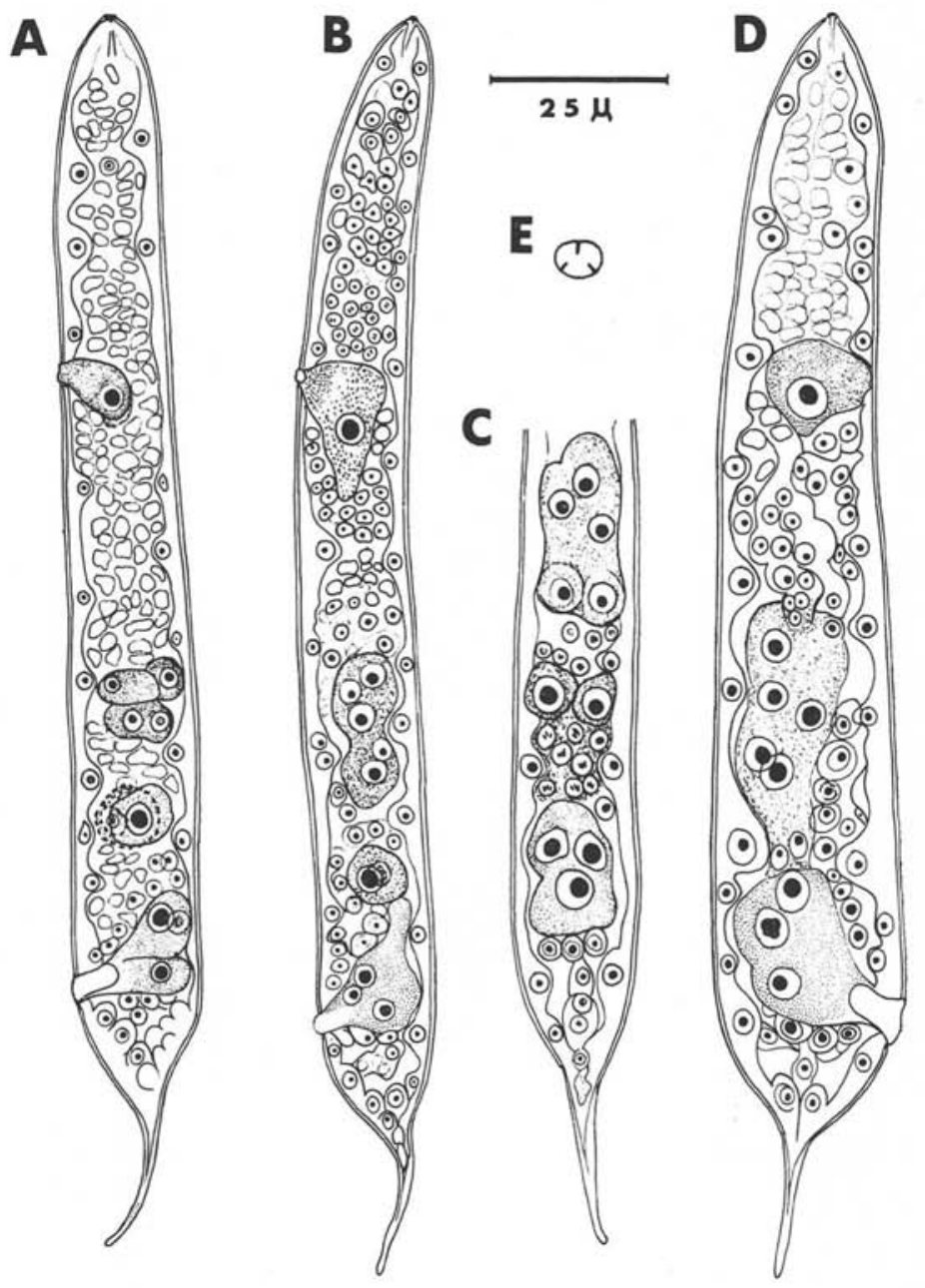

FIG. 18. - Wuchereria bancrofti. - A : larve de $70 \mathrm{~h}$ en vue latérale, à la $1^{\text {re }}$ division de $\mathrm{R}_{1}$. - B : idem, avec ébauche intestinale de 5 cellules. - C : idem, région postérieure en vue dorsale; 2 des 4 cellules filles de $R_{1}$ sont visibles. - D : larve de 4 jours en vue latérale. - E : bouchon anal vu de face 

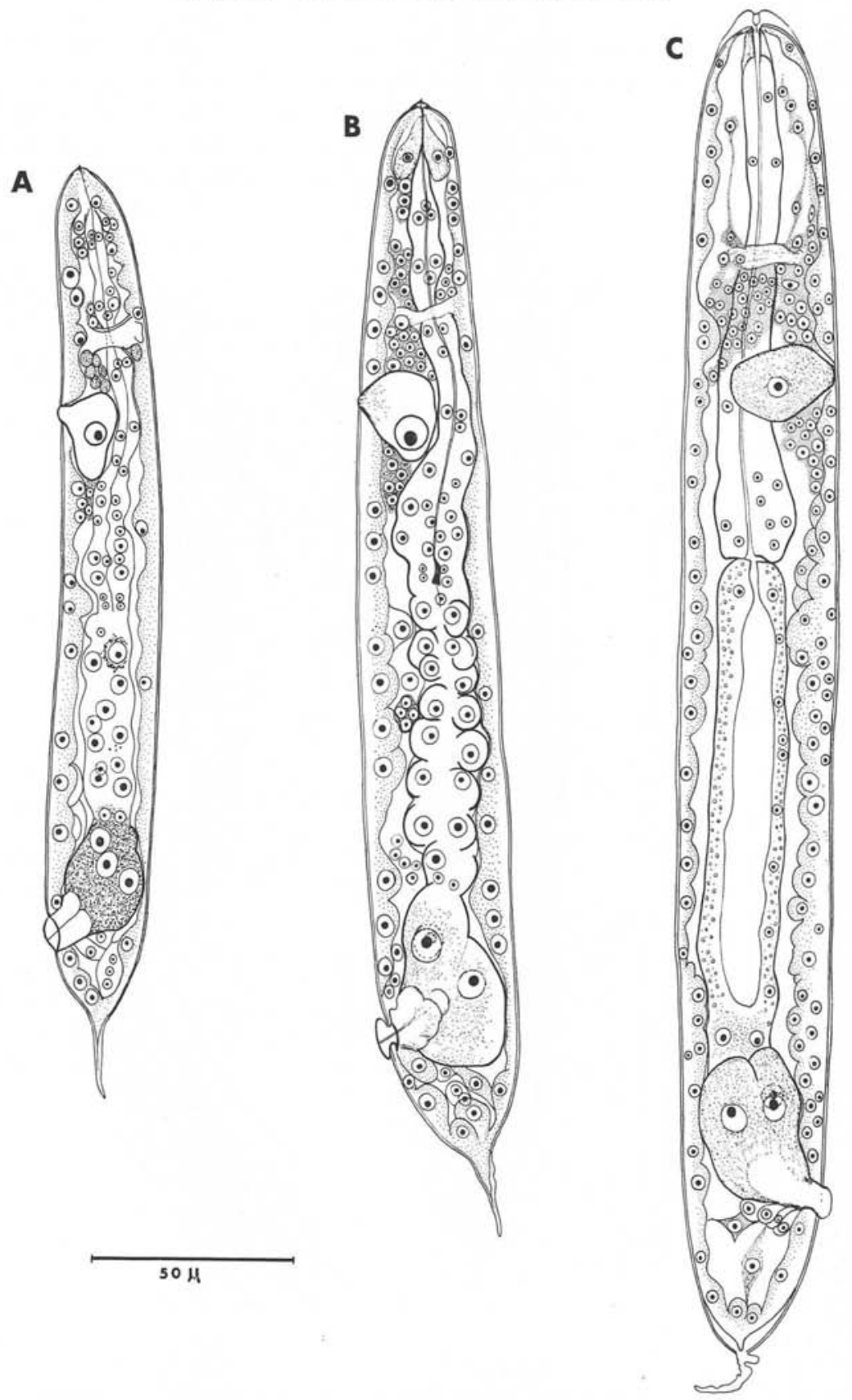

FIo. 19. - Wuchereria bancrofti, larves en vue latérale. - A: stade I âgé, en vue latérale. - B: larve de 5 jours, en mue I. - C: stade II jeune 
Par la suite, l'œsophage s'organise complètement, mais il s'arrête à une dizaine de $\mu$ du pore buccal, auquel il est relié par un simple axe cuticulaire ; les noyaux œsophagiens situés en arrière de la cellule excrétrice et les noyaux intestinaux se multiplient (fig. 19 A).

A la mue I, l'axe cuticulaire préœsophagien est bordé par une cellule ventrale et une cellule dorsale. L'œsophage comprend une région antérieure mince et une région
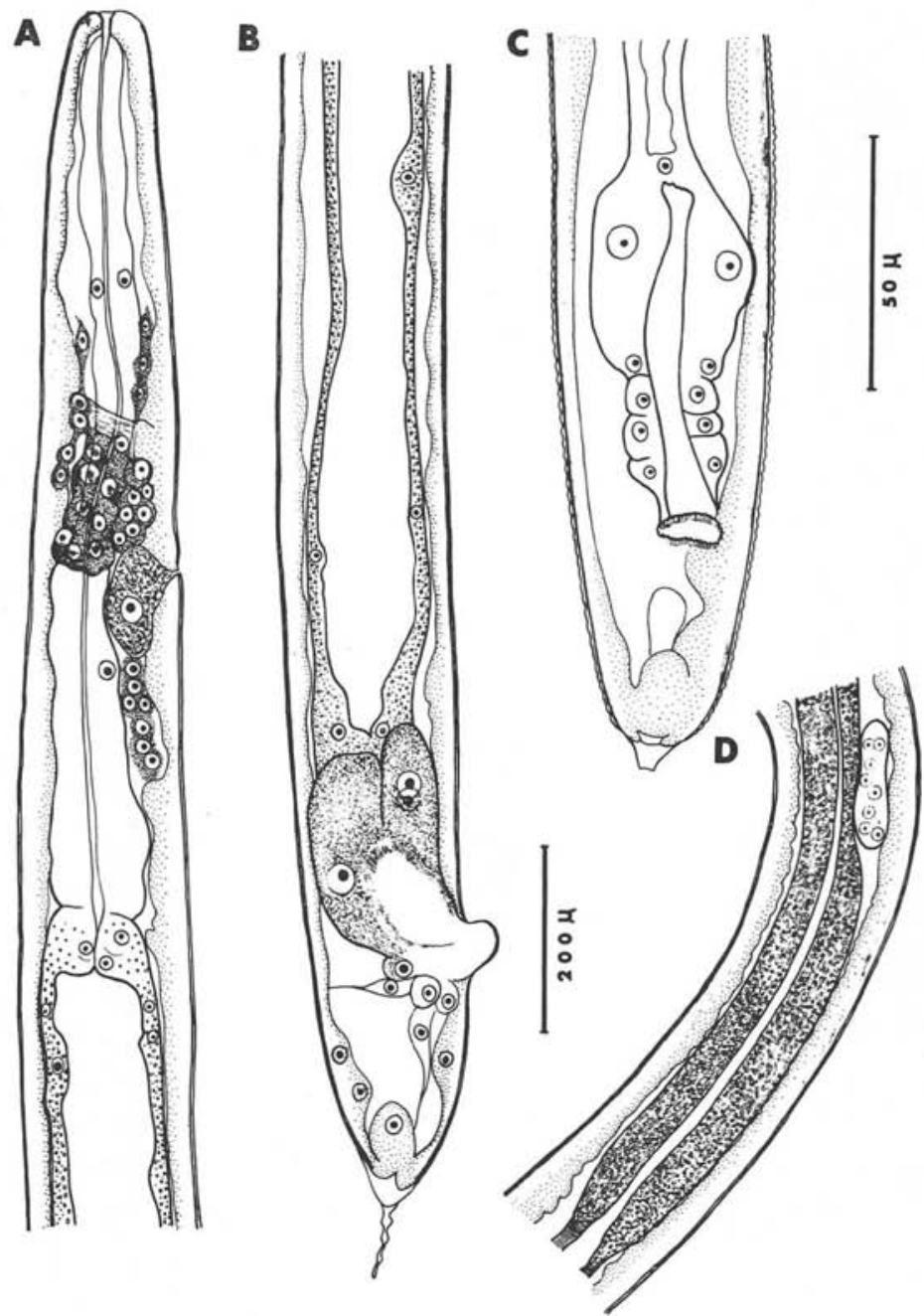

Fig. 20. - Wuchereria bancrofti. - A et B: stade II âgé de 10 jours, en vue latérale. - C: région caudale d'une larve de 10 jours au début de la mue II. - D : emplacement de l'ébauche génitale chez une forme infestante $q$ 
postérieure large. Le rectum est très volumineux ; le bouchon cuticulaire anal est séparé du cytoplasme des cellules rectales par une bordure striée radiairement. L'ébauche génitale de quatre cellules est située près de la face ventrale de l'intestin (fig. 19 B).

\section{DeuXIÈme STADE (fig. $19 \mathrm{C}$ et $20 \mathrm{~A}$ et B).}

L'exuvie du stade I persiste pendant tout le stade II dans la région caudale mais finit par être éliminée dans la région antérieure. Le tégument est formé par deux couches de cellules. A la bouche fait suite une invagination en forme d'entonnoir puis un tube cuticularisé court, entouré par un manchon cytoplasmique. L'intestin est creux et son cytoplasme se charge de réserves. Le rectum s'allonge et s'amincit; il comprend deux parties: la région proximale formée par trois volumineuses cellules et un tube cellulaire distal (fig. 20 B) ; l'ouverture de l'anus est festonnée.

A la mue II, les exuvies I et II sont expulsées ainsi que le bouchon anal.
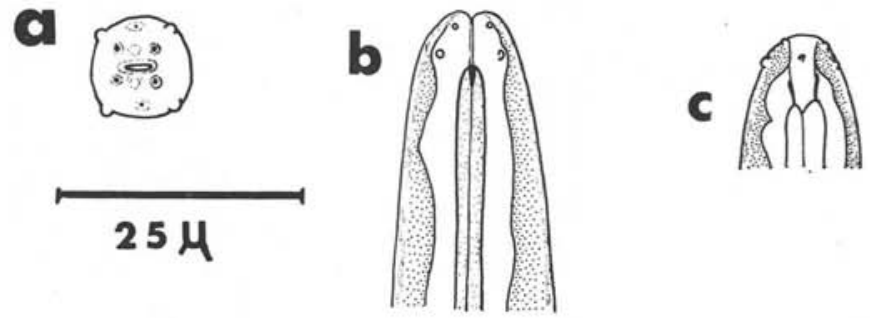

Fig. 21. - Wuchereria bancrofti, région céphalique d'une forme infes. tante. - A : vue apicale. - B: vue médiane. $-\mathrm{C}$ : vue latérale

Forme IN.NeSTANTE (fig. $20 \mathrm{D}, 21$ et 22).

La tête est ronde et porte quatre papilles labiales externes situées près de la bouche et quatre papilles céphaliques plus postérieures; deux légers reliefs cuticulaires sont situés dans le plan latéral près de la bouche; amphides un peu en avant du cercle céphalique. Bouche aplatie latéralement; tube préœsophagien sclérifié seulement près de l'œsophage et aplati aussi latéralement (fig. 21). Appareil excréteur comprenant un canal assez allongé, un sinus bien ouvert, une cellule excrétrice ovale ; les deux branches excrétrices partent de la région postérieure de cette cellule et ont une direction parallèle à l'axe du corps. Un massif ganglionnaire est situé en arrière de la cellule excrétrice (fig. $22 \mathrm{~A}$ ). Esophage musculaire allongé, se terminant en arrière de la cellule excrétrice. Esophage glandulaire, à cytoplasme grenu, plus long que l'œsophage musculaire. Intestin à paroi mince. Le rectum est très allongé et les glandes rectales sont bien individualisées. L'ébauche génitale plurinucléée est au niveau de l'intestin ou au niveau de l'œsophage. La queue a une forme en battant de cloche plus ou moins accentuée; les languettes caudales qui l'ornent ont une position variable (fig. $22 \mathrm{C}$, D et E); il y a généralement deux languettes, parfois une seule. 

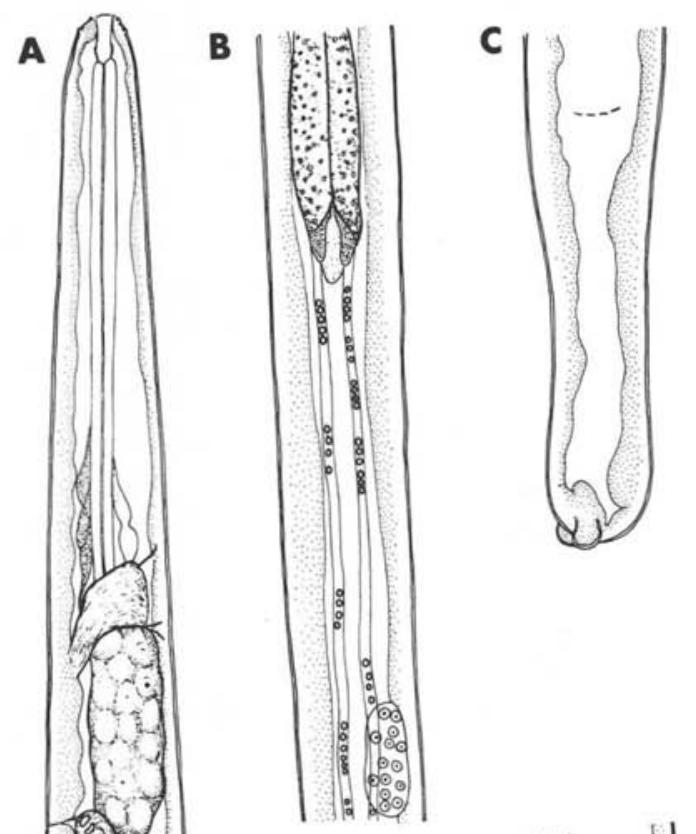

D
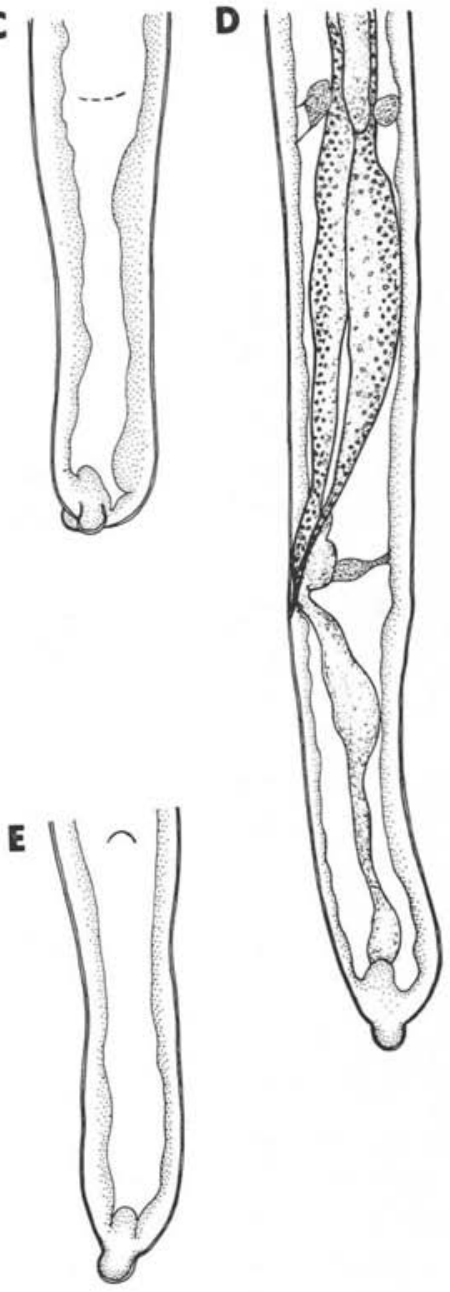

FIG. 22. - Wuchereria bancrofti, forme infestante. - A : région antérieure, vue latérale. - B: position de l'ébauche génitale chez une larve $\delta$. - C : région caudale d'une larve en vue dorsale. $-\mathrm{D}$ et $\mathrm{E}$ : région caudale d'une autre larve, en vue latérale et ventrale

\section{Conclusion.}

Chez $W$. bancrofti, nous retrouvons l'ébauche intestinale de cinq cellules, le prérectum de deux cellules, les trois cellules rectales et les quatre cellules filles de $R_{1}$ disposées dans les axes latéro-ventraux et latéro-dorsaux. La formation du rectum est clarifiée : les cellules $R_{2}, R_{3}$ et $R_{4}$, qui sécrètent le bouchon anal, s'allongent et s'éloignent 
de l'anus chez la forme infestante; elles forment les trois glandes rectales; un groupe de petites cellules, accolées à la portion distale du rectum au stade I, s'intercale entre les glandes rectales et l'anus chez la forme infestante et forme le tube rectal.

\section{Onchocerca gutturosa Neumann, 1910.}

Le cycle d'O. gutturosa a été établi par Steward en 1937, mais la morphologie larvaire de cette Filaire n'est pas approfondie. Nous avons eu la possibilité d'observer deux phases du cycle (la microfilaire et une larve de 72 heures) ; ces données, bien que fragmentaires, nous paraissent devoir être exposées.

\section{Matériel.}

Les observations ont été effectuées à Winches Farm, St. Albans (Laboratoire de la London School of Hygiene and Tropical Medicine) (6).

Les vaches sont assez fréquemment infestées par $O$. gutturosa; les tendons cervicaux, qui renferment les adultes et les peaux ombilicales, riches en microfilaires, sont récoltés aux Abattoirs.

Les larves du vecteur, Simulium ornatum, existent en abondance dans une rivière proche.

Une vache vivante (Caroline) a une faible infestation; les Simulies gorgées sur elle sont récoltées et mises en élevage à $23^{\circ}$.

\section{Dimensions.}

Microfilaire dermique : corps long de $275 \mu$ et large de $6 \mu$; noyau excréteur et noyau $R_{1}$ respectivement à $108 \mu$ et $190 \mu$ de l'apex ; distances $R_{1}-R_{2}$ et $R_{2}-R_{4}$ respectivement de $32 \mu$ et $8 \mu$; queue longue de $42 \mu$.

Stade I: larve de 72 heures : corps long de $165 \mu$ et large de $18 \mu$; anneau nerveux et pore excréteur respectivement à $38 \mu$ et $52 \mu$ de l'apex ; rectum haut de $12 \mu$; queue longue de $33 \mu$.

\section{Etude morphologique.}

LA MICROFILAIRE.

1) Microfilaires dermiques (fig. 23).

Tête à peine moins large que le reste du corps, portant un crochet sub-terminal exigu, latéral gauche (la position du crochet n'a pu être précisée que sur la larve en

(6) Nous remercions $\mathrm{M}$. le $\mathrm{P}^{r}$ Nelson, le $\mathrm{D}^{\mathrm{r}}$ Webbe et $\mathrm{M}$. Maylor qui nous ont reçue et aidée dans ce laboratoire. 
développement) et une plaque cuticularisée apicale (ou quatre aspérités ?) (fig. $24 \mathrm{D}$ ). Cuticule du corps épaisse et finement annelée. Queue assez robuste, pointue, fréquemment récourbée vers la face dorsale. Espace céphalique allongé, parcouru par deux

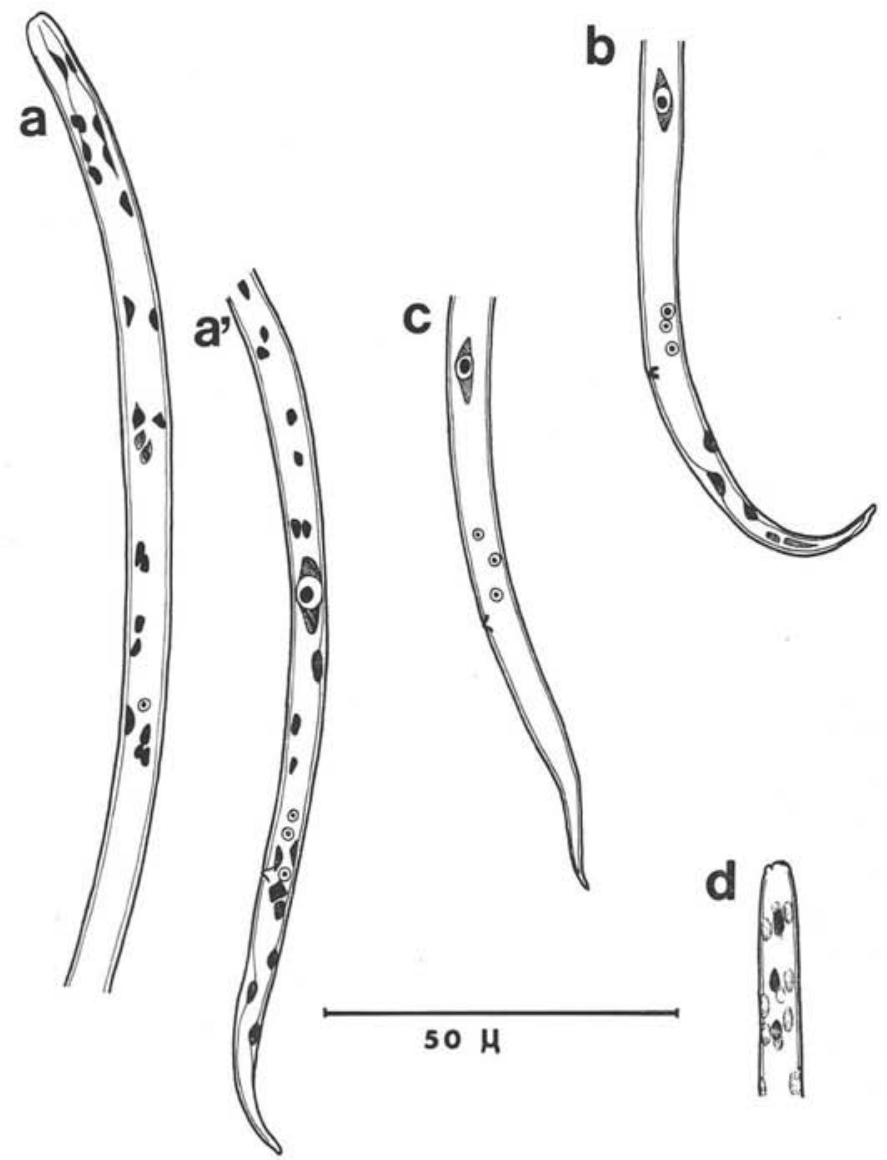

Fig. 23. - Onchocerca gutturosa. - A et $\mathrm{A}^{\prime}$ : une microfilaire dermique, en vue latérale. - B et $\mathrm{C}$ : différentes positions des cellules $\mathrm{R}$ chez d'autres microfilaires dermiques. - D : détail de la disposition des noyaux sous-cuticulaires

stries qui joignent l'apex à deux noyaux sous-cuticulaires antérieurs. Noyaux souscuticulaires très chromophiles, petits, généralement triangulaires, à cytoplasme plus clair; trois noyaux sous-zuticulaires sont généralement bien visibles dans la pointe caudale (deux dorsaux, un ventral); les noyaux sous-cuticulaires semblent être ali- 
gnés sur quatre files longitudinales dans la région antérieure dont deux semblent être latérales, et deux ventrale et dorsale. Cellule excrétrice : le cytoplasme et le pore excréteur ne sont pas visibles; le noyau excréteur est petit et rond.
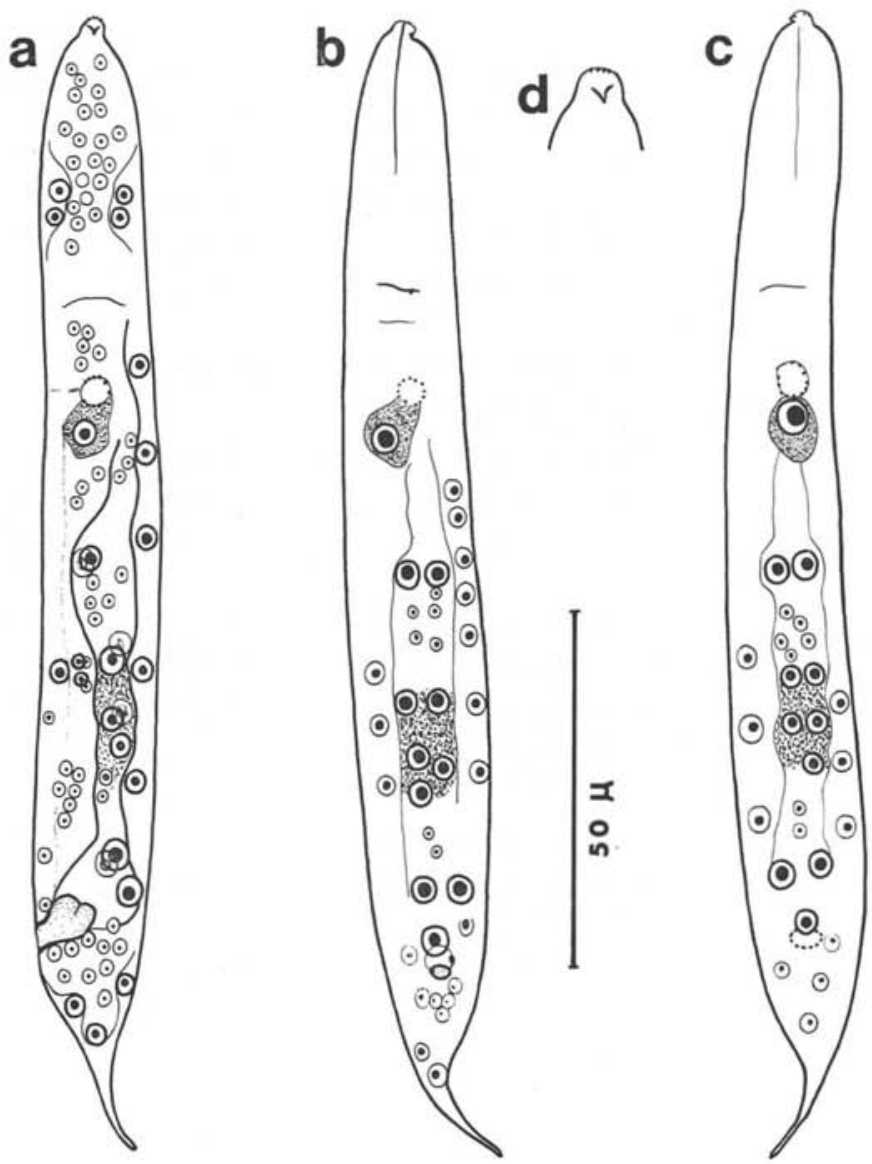

Fig. 24. - Onchocerca gutturosa, une larve de $72 \mathrm{~h}$. - A : vue latérale. - B : vue ventrale. - C : vue dorsale (en B et C, les noyaux de la colonne nucléaire et les noyaux sous-cuticulaires ne sont pas représentés dans la région antérieure). - D : crochet céphaiique vu de face, à main levée

Cellules $R: R_{1}$ est très éloigné de $R_{2}$ à $R_{4}$; cette cellule est ovoïde, souvent effilée dans son grand axe, avec un cytoplasme chromophile; le noyau est grand et ovoïde. $R_{2}, R_{3}$ et $R_{4}$ sont groupés près du pore anal, $R_{2}$ et $R_{3}$ étant souvent plus rapprochés entre eux ; seuls les noyaux, petits et ronds, sont visibles. 
2) Microfilaires prélevées dans l'utérus.

Ces microfilaires prennent une légère teinte bleutée, homogène; aucune cellule ne se colore sélectivement.

LARVE DE 72 HEURES (fig. 24).

Les trois images représentant cette larve montrent que la région située en avant de la cellule excrétrice n'est pas organisée ; les cellules sous-cuticulaires sont volumineuses, la région centrale de la larve est remplie de cellules polygonales à petits noyaux ronds et de taille égale. L'anneau nerveux est peu distinct. La cellule excrétrice a un cytoplasme développé ; son noyau est rond et volumineux; le pore excréteur se dilate pendant le séjour dans le milieu d'observation. Postérieurement à la cellule excrétrice l'organisation est plus avancée ; d'arrière en avant, on voit :

- le bouchon rectal, petit, non saillant et les trois cellules rectales qui ne forment pas encore un rectum bien défini ;

- un cordon plein (bien visible en vue latérale) présentant différentes structures nucléaires et cytoplasmiques : deux petits noyaux près du rectum (prérectum), puis cinq gros noyaux ronds et vésiculeux entourés par un cytoplasme grenu (ébauche intestinale); ensuite cinq petits noyaux et deux gros noyaux ronds puis, dans la portion plus étroite située en arrière de la cellule excrétrice, trois petits noyaux, l'ensemble formant les ébauches valvulaire et œsophagienne ;

- quatre (?) petits noyaux situés près de la face ventrale du cordon intestina: pourraient être l'ébauche génitale.

\section{Conclusion.}

O. gutturosa, bien que très incomplètement étudiée, nous apporte les éléments indispensables à l'interprétation des figures représentant $O$. volvulus (cf. Bain, 1969 a) ; on constate que ces deux espèces, malgré une morphologie un peu atypique (existence de deux grosses cellules œsophagiennes, cordon digestif non rétréci au niveau de la valvule œsophagienne) s'interprètent de la même façon que les autres Filaires vivipares.

\section{Rectifications morphologiques}

\section{Foleyella candezei (Fraipont, 1882).}

En $1970 a$, nous n'avions pas observé la division de la cellule $R_{1}$ et nous représentions six cellules intestinales. Nous avons repris ce matériel pour apporter diverses précisions.

La cellule $\mathrm{R}_{1}$ se divise vers la $48^{\circ}$ heure (à $24-26^{\circ}$ ) ; l'ancien emplacement du corps interne est marqué par quelques granules réfringents (fig. 25). 
Chez une larve de $72 \mathrm{~h}$ (fig. 25), le cordon digestif est mis en place, sauf dans la région située en avant de la cellule excrétrice ; le rectum comprend les trois cellules $R_{2}$, $\mathrm{R}_{3}$ et $\mathrm{R}_{4}$ et les cellules du futur tube rectal qui sont accolées à la paroi de $\mathrm{R}_{4}$; l'intestin

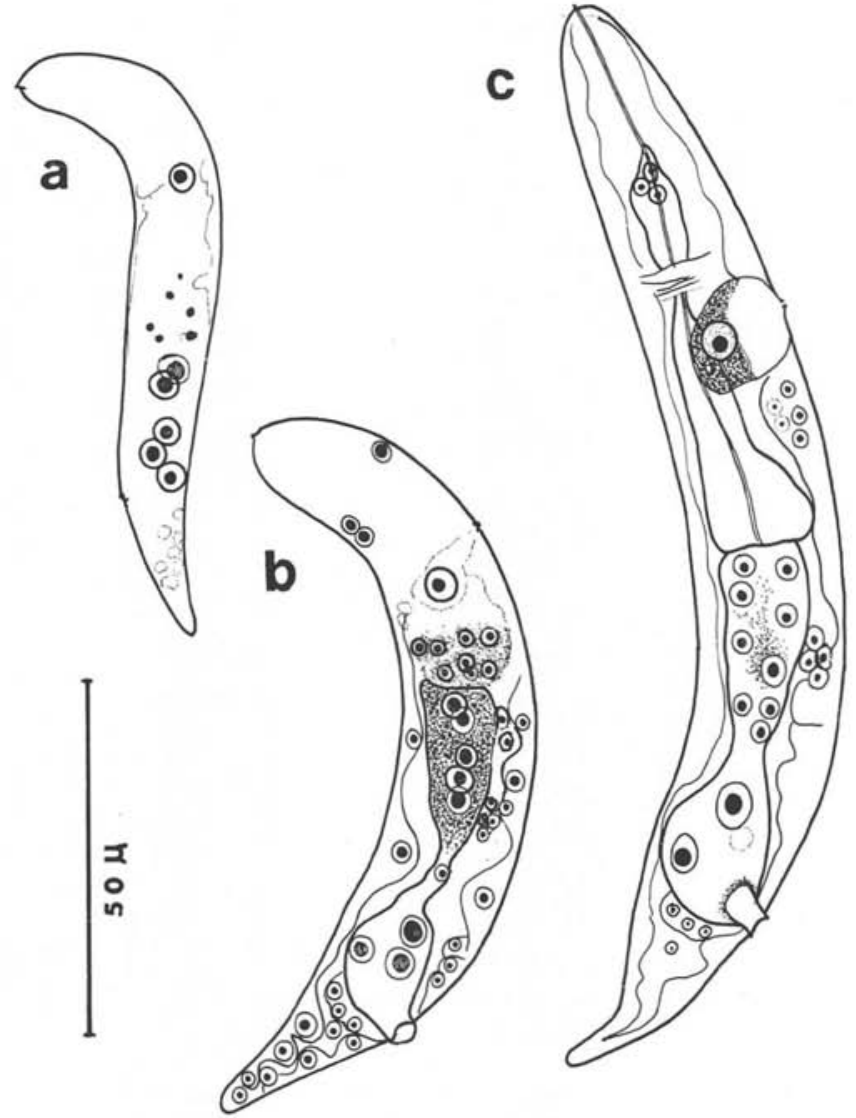

Fig. 25. - Foleyella candezei, stade I. - A: larve de 48 h ; R, divisé une fois. - B: larve de $72 \mathrm{~h}$ avec l'ébauche intestinale de 5 cellules. - C: larve de $96 \mathrm{~h}$, juste avant la mue I

renferme cinq cellules; il est relié au rectum par un isthme étroit de deux petites cellules (fig. 25 B) ; l'œsophage est un gros bourgeon multinucléé.

Les cellules intestinales se multiplient rapidement (larve de 96 h, fig. 25) ; l'organisation de l'œsophage progresse vers l'avant ; l'ébauche génitale est formée par quatre cellules. 
A la mue I, la région buccale s'invagine ; entre la bouche et l'œsophage subsiste un segment préœsophagien bordé par deux massifs cellulaires. Au cours du stade II, un tube pharyngien cuticularisé s'intercale entre la cavité buccale et l'œsophage (fig. 26).
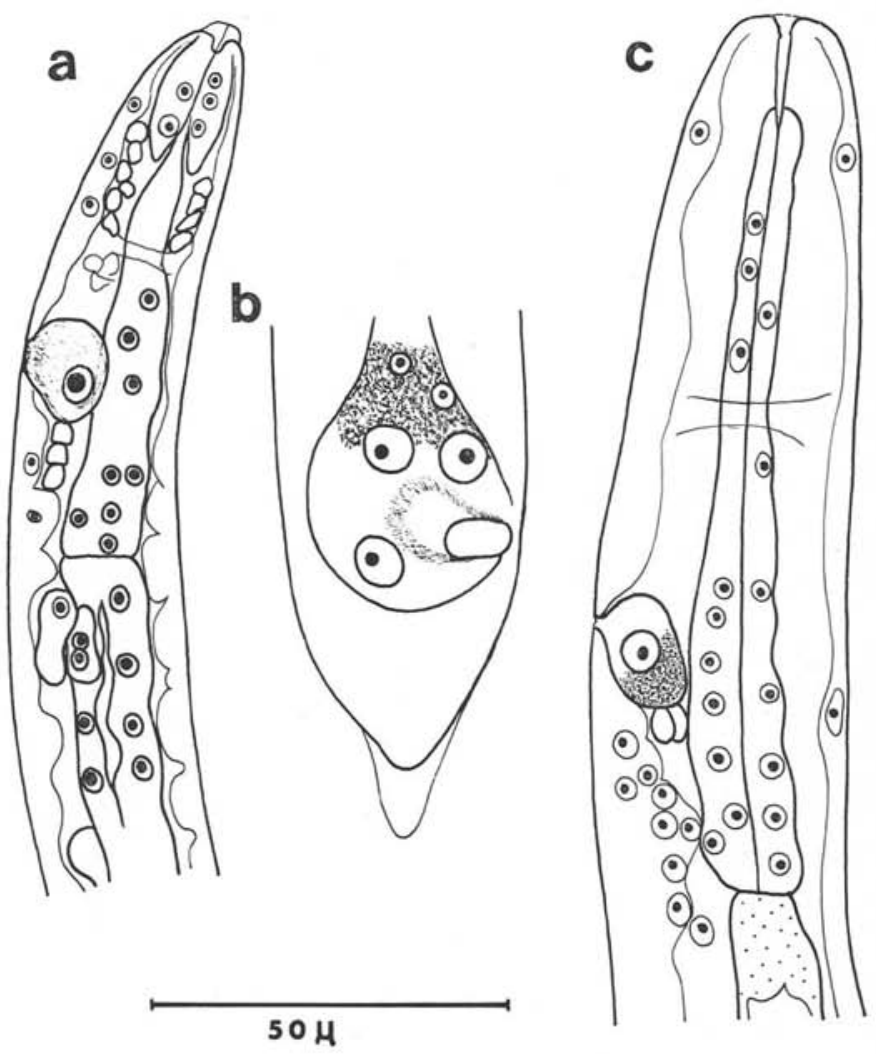

FIG. 26. - Foleyella candezei. - A : mue I. - B : région caudale d'un stade II en vue semi-latérale. C: région antérieure d'un stade II en vue latérale

Oncbocerca volvulus (Leuckart, 1893).

La figure 27 précise que la région buccale du stade II a la même organisation que celle des autres Filaires : elle comprend une petite invagination buccale et un court segment pharyngien. Les figures $27 \mathrm{~B}$ et $\mathrm{C}$ montrent les deux positions de l'ébauche génitale chez les formes infestantes: au niveau de l'intestin chez les larves $\hat{\sigma}$ (B), au niveau de l'œsophage glandulaire chez les larves $q$ (C). 
a
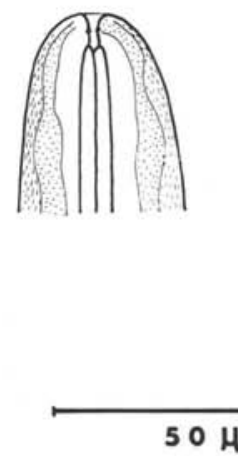

b

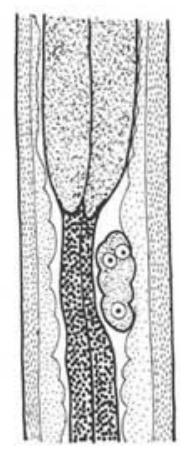

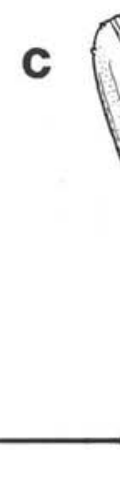

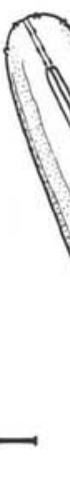

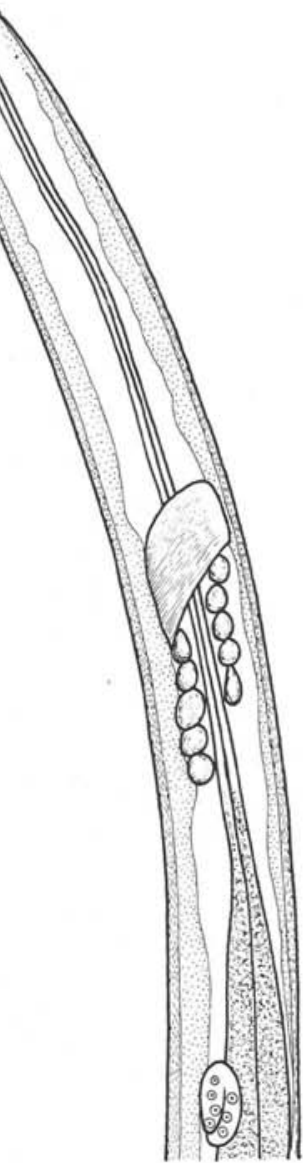

FIG. 27. - Onchocerca volvulus. - A: région céphalique d'un stade II. - B : ébauche génitale au niveau de l'intestin chez une forme infestante $\delta^{\star}$, en vue latérale. - C : région antérieure d'une forme infestante ${ }_{+}$, en vue latérale

\section{III. - CONCLUSIONS}

Nous avons observé les cycles d'un Spiruride primitif (Spirura), d'un Spiruride évolué (Draschia), d'une Filaire ovipare (Serratospiculum), et de neuf Filaires vivipares réparties dans les familles des Setariidae (Setaria) et des Onchocercidae (Dirofilariinae : deux Foleyella; Onchocercinae : deux Dipetalonema, deux Onchocerca, un Wuchereria ; Eufilariinae : Saurositus); dans ce vaste groupe des Spirurina, les larves à l'éclosion ont la même anatomie èt le déroulement de l'organogenèse s'effectue suivant un plan constant. 


\section{La microfilaire.}

Avant de décrire l'organogénèse chez le vecteur, nous devons préciser l'anatomie de la larve à l'éclosion ; bien que notre contribution personnelle à cette question soit faible, il nous semble donc utile de rappeler quelques notions importantes sur l'anatomie des microfilaires au début de nos conclusions.

\section{A) Anatomie d'une microfilaire (fig. $28 \mathrm{~A}$ et $\mathrm{A}^{\prime}$ ).}

Les microfilaires, quelles que soient les espèces auxquelles elles appartiennent, ont une organisation constante qui a été mise en évidence depuis longtemps par la coloration au Giemsa, les colorations vitales et la coloration au vert de méthyle-Pyronine (Noe, 1901 ; Rodenwalt, 1908 ; Golvan, 1957) ; certaines structures ont été précisées récemment par l'utilisation de nouvelles techniques : observation au microscope à UV (Taylor, 1960), au microscope électronique (Kozek, 1968 ; Mac Laren, 1969) et mise au point de colorations histochimiques (Laurence et Simpson, 1968).

La microfilaire est allongée et mobile, la tête porte un crozhet cuticularisé, probablement actionné par deux cellules antérieures mises en évidence par Taylor («hook muscle cells ») (1960) et par Laurence et Simpson (1968); elles sont parfois colorées sélectivement par l'Azur II (Bain, 1970). La cuticule est doublée par une couche de cellules sous-cuticulaires à cytoplasme fibrillaire («muscle cells » de Taylor, 1960), qui est responsable de la mobilité de la microfilaire. Le corps de la microfilaire est occupé par les noyaux de la colonne nucléaire ; celle-ci s'interrompt sur une étroite bande transversale située vers le 1/4 antérieur de la microfilaire : l'espace anhyste ainsi formé correspond à l'anneau nerveux ; Taylor (1960) a montré qu'il était bordé par deux cellules initiales nerveuses. Certains noyaux de la colonne nucléaire sont colorés sélectivement par les colorants vitaux ; le noyau excréteur est relié au pore excréteur par le cytoplasme de la cellule excrétrice qui est plus ou moins coloré et est situé vers le tiers antérieur de la microfilaire ; les quatre noyaux $R_{1}, R_{2}, R_{3}$ et $R_{4}$ (appelés autrefois « G-cells 》 par Rodenwalt, 1908) sont situés dans la région postérieure de la microfilaire. Le noyau $R_{1}$ est souvent plus gros que les trois autres et fréquemment éloigné du groupe $R_{2}$ à $R_{4} ; R_{4}$ est situé près du pore anal. En plus de ces noyaux mis régulièrement en évidence, Kobayashi, en 1940, signale l'existence, chez Wuchereria bancrofti, de deux cellules initiales de l'œsophage musculaire et de deux autres cellules initiales de l'œsophage glandulaire.

Dans la région moyenne du corps, en avant de $\mathrm{R}_{1}$, les microfilaires présentent fréquemment une masse anhyste, réfringente, de forme et d'affinités tinctoriales variables, le corps interne. Il s'agit d'une substance de réserve (Coutelen, 1929).

Laurence et Simpson (1968) ont mis en évidence un axe qui s'étend de la tête de la microfilaire au corps interne et qu'ils nomment « pharyngeal thread », autour duquel se formera l'œsophage, que nous désignons sous le nom d'axe œsophagien.

La tête porte une paire de petites formations chromophiles, les \& roten Mundgebilde » de Fülleborn (1913), que Kozek assimile à des amphides (1968) ; il existe une paire de formations analogues au niveau de la queue (« Schwanzgebilde ») que le même auteur (1968) assimile aux phasmides. 
L'armature céphalique a été particulièrement bien étudiée par Laurence et Simpson (1968) ; elle comprend un crochet subapical qui borde le pore buccal et souvent, du côté opposé au crochet, des pointes cuticulaires.

Le plan d'organisation de la microfilaire est donc déjà bien connu ; nous pouvons y ajouter deux précisions :

a) sur la position du crochet céphalique : l'observation de trois espèces à microfilaires de grande taille (Dipetalonema viteae, Setaria labiatopapillosa et Wuchereria bancrofti) a montré que le crochet céphalique est situé sur le flanc gauche de la microfilaire. Les pièces accessoires sont situées sur le flanc droit;

b) sur les noyaux sous-cuticulaires : généralement, les noyaux sous-cuticulaires sont représentés sous l'aspect de deux files longitudinales situées dans le plan de la figure. Fülleborn, en 1913, représente trois files de noyaux sous-cuticulaires. Chez D. viteae et Onchocerca gutturosa, les cellules sous-cuticulaires nous ont paru être disposées en quatre files longitudinales.

B) Analogies entre l'anatomie d'une microfilaire et celle d'une larve de Filaire ovipare ou de Spiruride.

Les liens phylétiques entre les Spirurides, sensu lato, et les Filaires sont si étroits que les limites entre ces deux groupes sont purement conventionnelles.

L'œuf de Draschia megastoma (fig. 3) libère un petit embryon, mince, allongé, qui a la silhouette et la morphologie interne d'une microfilaire: cellules sous-cuticulaires, colonne nucléaire, cellule excrétrice et cellule rectale $R_{1}$ à $R_{4}$.

La larve nouvellement éclose de Spirura guyanensis (ou celle de Serratospiculum tendo) est mobile mais diffère beaucoup à première vue d'une microfilaire par sa grande taille, sa robustesse et son organisation assez avancée (fig. 1) : œsophage formé dans la région postérieure, sac intestinal ébauché et rempli de granules métaboliques. Mais ce type de larve possède les quatre cellules rectales caractéristiques des microfilaires (nous n'avons pas vu nous-mêmes la cellule $\mathrm{R}_{1}$ chez les Filaires ovipares, mais Anderson la représente très clairement chez deux Diplotriaenidae en 1957 et 1962). La présence de ces cellules, et principalement de la cellule $R_{1}$, permet de préciser les analogies entre les structures de la larve de Spiruride et celles de la microfilaire : la cuticule de la larve de Spiruride est tapissée par de gros noyaux qui sont l'équivalent des noyaux sous-cuticulaires; la région antérieure de la larve de Spiruride est inorganisée et remplie de gros noyaux, assimilables aux noyaux de la colonne nucléaire; les deux gros noyaux, appendus à l'apex de la larve de $S$. guyanensis semblent être les équivalents des deux " hook-muscle cells ; les granules métaboliques contenus dans le sac intestinal de la larve Spiruride correspondent au corps interne. Chez la microfilaire les noyaux intestinaux ne sont pas visibles mais nous allons voir qu'au début du développement, ils apparaissent à l'emplacement du corps interne ; il est donc probable que le sac intestinal existe chez la microfilaire, mais l'extrême réduction des dimensions ne permet pas de le discerner. 
2. L’organogenèse (fig. 28 et 29).

Le point le plus délicat de l'organogenèse larvaire des Filaires était le devenir de la cellule $\mathrm{R}_{1}$; en $1970(b)$, nous avons montré qu'elle est à l'origine de toute la musculature de l'adulte ; nos observations sur deux Spirurides confirment ces résultats ; Laurence (1971) apporte également un appui à notre interprétation en décrivant chez Brugia pahangi (Buckley et Edeson, 1956), la migration des quatre cellules filles de $\mathrm{R}_{1}$ vers la périphérie du corps. La cellule $\mathrm{R}_{1}$, initiale mésenchymateuse, a le même aspect que les trois vraies cellules rectales car, comme elles, elle est d'origine ectodermique.

Dans ces conclusions, nous laissons donc de côté la question de la cellule $R_{1}$ et nous exposons le reste de l'organogenèse en insistant sur les structures qui restaient imprécises.

\section{A) Formation du rectum.}

Il comprend les trois cellules rectales $\left(R_{2}\right.$ et $R_{3}$ latéro-ventrales; $R_{4}$ dorsale) qui ont une grande activité glandulaire aux stades I et II puisqu'elles sézrètent le bouchon anal ; mais le rectum comprend également un groupe de cellules précocement accolées aux précédentes, près du pore anal ; au cours du stade II et surtout pendant la maturation de la forme infestante ces petites cellules forment un tube rectal qui s'intercale entre les cellules $R_{2}$ à $R_{4}$ et l'anus.

Le bouchon anal est essentiellement sécrété au premier stade; à la mue I, il se décolle des cellules $R_{2}$ à $R_{4}$; l'espace ainsi créé est occupé par une bordure striée radiairement.

\section{B) Le prérectum.}

L'intestin et le rectum sont reliés par un isthme étroit, souvent très allongé, binucléé (probablement une cellule dorsale et une cellule ventrale). Cet organite, non décrit par les auteurs précédents, est toutefois clairement représenté par Anderson chez une Filaire ovipare (1957).

\section{C) Formation de l'intestin.}

$\mathrm{Si}$ le nombre des cellules initiales qui constituent l'intestin est difficile à préciser chez les Spirurides, il semble être égal à cinq chez les Filaires ovipares (Anderson, 1957 et 1959) et chez la plupart des Filaires vivipares.

Les divisions nucléaires de l'ébauche intestinale débutent assez tardivement, un peu avant la mue I. A ce moment l'intestin se creuse et commence à se remplir de déchets du métabolisme; ils sont expulsés à la mue II, quand s'effectue la communication entre les lumières intestinale et rectale.

D) Formation de l'asophage (fig. 28).

La majeure partie des noyaux œsophagiens semble être déjà présente chez la microfilaire. Pour former l'œsophage, ils se regroupent autour de l'axe cuticulaire qui s'étend de l'apex jusqu'à l'ébauche intestinale de la microfilaire. Chez la microfilaire, cet axe 


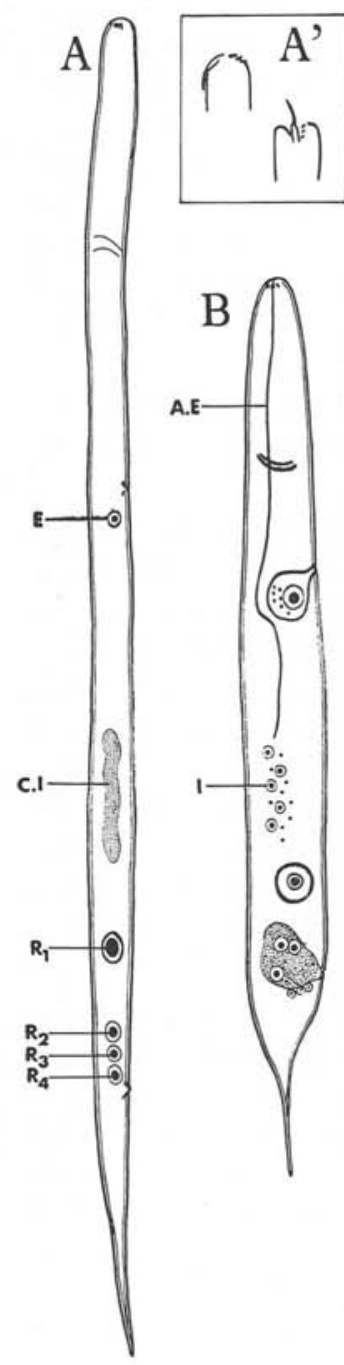

Microfilaire

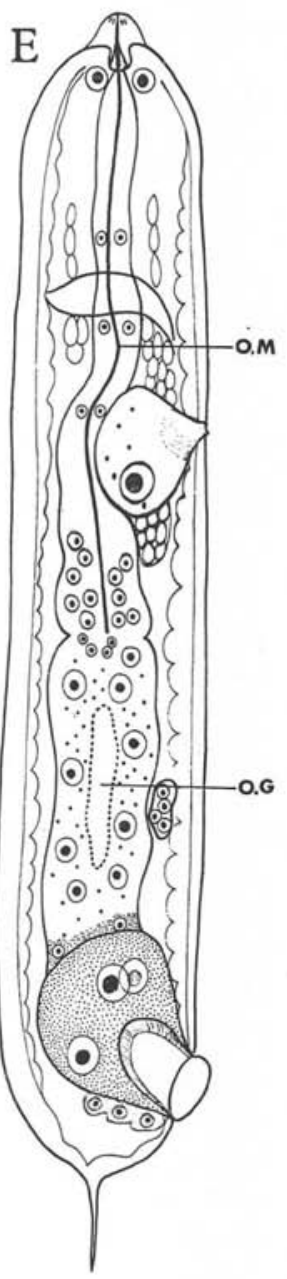

Stade I

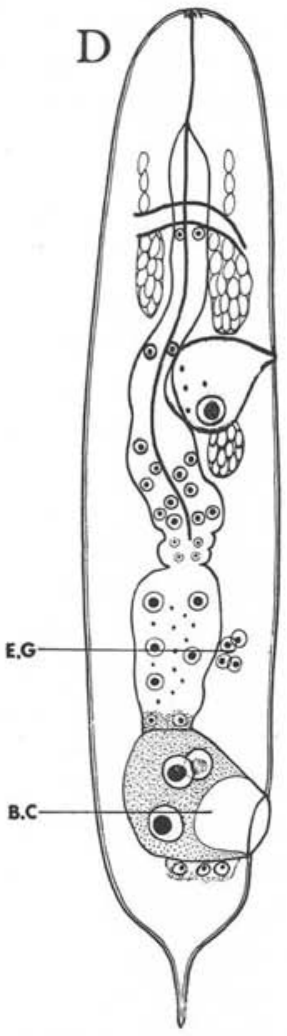

Fig. 28. - Schćma indiquant l'organogénèse d'une Filaire vivipare (le mésenchyme, issu de la cellule $R_{1}$ n'est plus représenté à partir de la figure $\mathrm{D}$ ) 
n'est en général visible que dans la région céphalique; il n'est entièrement visible qu'exceptionnellement chez les microlaires à frais; mais il devient net dès le début du développement larvaire.

L'œsophage se constitue progressivement d'arrière en avant et offre, dès sa formation, une structure hétérogène : la partie postérieure est trapue et riche en noyaux tandis que la partie antérieure est allongée avec des noyaux dispersés. Dans certains cas (S. labiatopapillosa, cf. Bain, 1970 c), l'œsophage paraît être formé par trois ébauches: une large ébauche postérieure, une courte ébauche intermédiaire située dorsalement par rapport à la cellule excrétrice et une longue ébauche antérieure. Ces trois ébauches pourraient correspondre respectivement, d'arrière en avant, au bulbe, à l'isthme et au corpus ; mais chez les autres Filaires ces trois ébauzhes seraient plus précocement fusionnées.

L'ébauche antérieure de l'œsophage est initialement éloignée de l'apex de la larve ; à la fin du premier stade elle s'étend vers l'avant, et, à la mue I, il ne subsiste entre la bouche et l'œsophage qu'un court segment cuticularisé.

L'œsophage, une fois mis en place, subit une importante croissance en longueur qui s'effectue durant le deuxième stade et la maturation de la forme infestante. La région œsophagienne postérieure, située en arrière de la cellule excrétrice se modifie : les multiplications nucléaires sont abondantes et entraînent un épaississement de la paroi œsophagienne. Celle-ci renferme finalement deux types de noyaux: des noyaux ovoïdes espacés qui bordent la lumière œsophagienne, et de nombreux noyaux arrondis qui constituent un épais cortex œsophagien. Les noyaux axiaux étant identiques à ceux de la région antérieure de l'œsophage, nous pensons que ce sont les noyaux œsophagiens sensu stricto, tandis que les noyaux du cortex sont les noyaux des glandes œsophagiennes. Cette partie postérieure de l'œsophage se charge de granules de sécrétion. La région antérieure de l'œsophage, ou œsophage musculaire ne subit guère de modifications et les multiplications cellulaires y semblent riares.

Chez les Spirurides, les noyaux de l'œsophage sont appliqués contre l'axe œsophagien chez la larve nouvellement éclose. Au cours du développement, l'œsophage s'individualise par un regroupement des noyaux et une croissance cytoplasmique ; au début du premier stade, il y a un type rhabditoïde qui s'estompe rapidement. Le deuxième stade est marqué par une abondante multiplication nucléaire dans l'œsophage postérieur qui affecte surtout les noyaux glandulaires. Ce plan d'organisation est donc identique à celui des Filaires vivipares ; l'existence d'un œsophage tripartite (bulbe, isthme et corpus du type ancestral Rhabditide) chez la larve à l'éclosion des Spirurides explique la formation de l'œsophage de certaines Filaires, par exemple, S. labiatopapillosa, à partir de trois ébauches indépendantes (Bain, 1970).

E) Transformation de la région céphalique (fig. 29).

Chez les Filaires vivipares, la région céphalique est très exiguë et l'étude de son évolution est difficile. Plusieurs problèmes concernant cette région ont été clarifiés grâce aux observations effectuées chez les larves de Spirurides.

a) Morphogenèse du pharynx chez les Spirurides. La morphogenèse du pharynx 


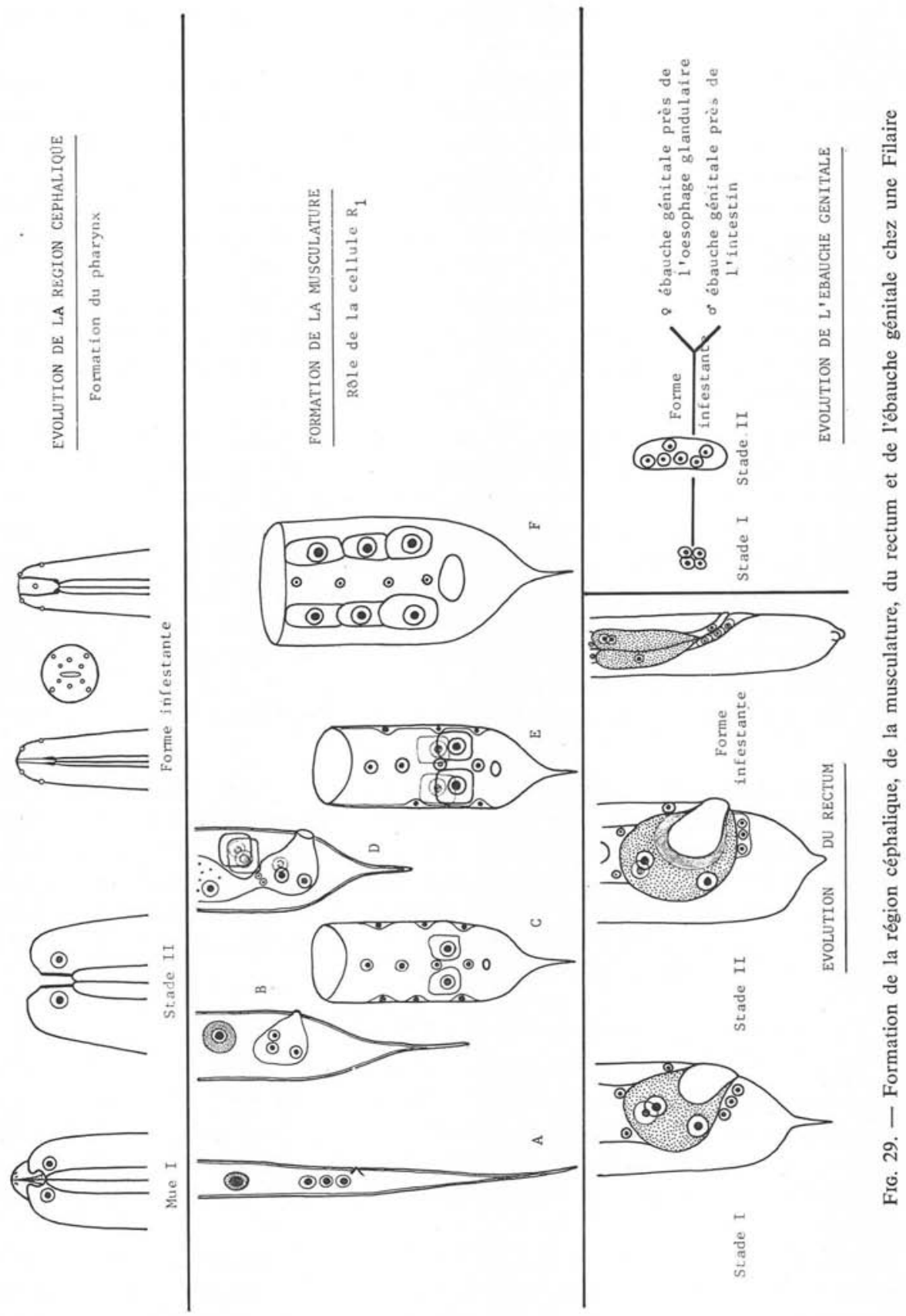


a été suivie sur D. megastoma (fig. 7), mais s'applique aux autres Spirurides (Quentin, $1969 a$ et $b$ et 1970).

Le pore buccal de la larve du premier stade est relié à l'œsophage par un segment cuticulaire plein. A la mue I, la région péribuccale s'invagine et forme une petite cavité en entonnoir, qui arrive directement au contact de l'œsophage. Pendant le stade II, un tube cuticulaire vient s'intercaler entre cette cavité buccale et l'œsophage ; ce tube est d'abord très court, puis s'allonge fortement; il est très szlérifié ; il constitue le pharynx. La jonction de la cavité buccale et du pharynx est soulignée par des dents (quatre chez D. megastoma, mais trois ou six chez d'autres Spirurides).

L'ébauche pharyngée du jeune deuxième stade est bordée dorsalement et ventralement par deux très gros noyaux ronds, à nucléole volumineux ; ils persistent jusqu'au stade infestant. Nous pensons qu'ils jouent un rôle dans la formation du pharynx et qu'ils sécrètent l'épaisse cuticule de cet organite.

b) Morphogenèse de la capsule buccale chez les Filaires (fig. 29). Chez la microfilaire et la larve du premier stade, le pore buczal est relié à l'œsophage par un court segment cuticulaire, qui est l'apex de l'axe œsophagien. A la mue I, la cuticule péribuccale s'invagine et forme une petite cavité en forme d'entonnoir. Au stade II, l'œsophage est séparé de la bouche par un tube cuticularisé, formé par un ou deux anneaux superposés; chez deux grandes espèzes (S. labiatopapillosa et $W$. bancrofti), ce tube apparaît bordé par deux gros noyaux médians (dorsal et ventral). Leur nombre et leur position font penser qu'ils pourraient provenir de la transformation des « hook muscle cells ». Chez la forme infestante, ce tube n'est sclérifié qu'à sa jonction avec l'œsophage. Il est aplati latéralement, comme la bouche. Il est habituellement nommé : «capsule buccale».

c) Homologie entre le pharynx des Spirurides et la capsule buccale des Filaires. Ainsi, dans les deux groupes des Spirurides et des Filaires, l'évolution de la région céphalique est la même jusqu'au début de la mue I ; ensuite, il se forme chez les Spirurides un volumineux pharynx sécrété par les deux gros noyaux médians et chez les Filaires un petit tube cuticularisé, lui aussi bordé par deux gros noyaux médians. Nous pensons donc que la cavité buccale des Filaires est l'homologue de la pièze que nous nommons pharynx chez les Spirurides.

F) Formation de l'ébauche génitale (fig. 29).

Chez $S$. guyanensis, les cellules génitales sont grandes ; elles peuvent être sûrement dénombrées. Au début du développement, l'ébauche génitale est formée par quatre cellules; chacune est bien délimitée ; il existe deux cellules postérieures volumineuses et deux cellules antérieures plus petites, disposées l'une derrière l'autre. Plus tard, les limites cellulaires s'estompent, mais l'ébauche génitale reste à quatre noyaux pendant tout le premier stade.

Chez les différentes espèces de Filaires où les structures étaient assez nettes, quatre noyaux ont été comptés dans l'ébauche génitale, au stade I. Ce chiffre correspond aux observations effectuées chez les autres Nématodes (Nigon, in Grassé, 1965). Chez 
S. labiatopapillosa, nous avons observé deux paires de petites cellules latéro-ventrales, situées à mi-hauteur de l'intestin. En raison de leur nombre et de leur position, nous pensons que ce sont les initiales génitales qui finiront par se fusionner dans le plan sagittal. L'ébauche génitale subit une seule phase de multiplication cellulaire au cours du stade II, puis elle arrête son développement. A la fin du deuxi ̇̀me stade et chez la forme infestante, l'ébauche génitale est située soit au niveau de l'œsophage, soit au niveau de l'intestin. Chabaud a observé pour la première fois ces deux positions chez D. viteae (1954) et en a donné une interprétation : chez les larves + , l'ébauche génitale, située initialement près de l'intestin, migre vers la région antérieure où s'ouvrira la vulve de l'adulte.

\section{G) Appareil excréteur.}

La cellule excrétrice est déjà visible chez la microfilaire. Elle devient très volumineuse dès le début du développement. Au deuxième stade, la naissance des canaux excréteurs latéraux est bien visible. Chez la forme infestante, la cellule excrétrice est réduite, souvent difficile à voir.

\section{H) Système nerveux et appareil sensoriel.}

De nombreuses cellules de la colonne nucléaire se regroupent sous l'anneau nerveux ; la taille des cellules augmente mais aucune division n'a été observée. Finalement. il existe quatre massifs ganglionnaires : un ventral, souvent le plus long, deux latéraux et un dorsal court. L'anneau nerveux est incliné vers la face ventrale. Des cellules ganglionnaires reliées à l'anneau nerveux sont dirigées vers l'apex. Un petit massif ganglionnaire est appendu à la cellule excrétrice.

L'appareil sensoriel chez les Filaires vivipares n'est bien visible que chez la larve infestante ; en plus des deux amphides, il est régulièrement constitué par quatre papilles labiales externes, disposées en carré près de la bouche, et quatre papilles céphaliques disposées de la même façon mais plus postérieurement.

Les nouveaux cycles filariens que nous décrivons ici montrent que la microfilaire comprend, outre un revêtement ectodermique simplement constitué par quatre files de cellules, plusieurs bourgeons :

Les bourgeons œsophagiens et rectaux $\left(R_{2}, R_{3}, R_{4}\right.$ et tube rectal), d'origine ectodermique.

Le bourgeon intestinal, généralement à cinq cellules, d'origine endodermique.

Le bourgeon mésenchymateux, réduit à une cellule unique $\left(R_{1}\right)$.

Les larves nouvellement écloses des Filaires ovipares et des Spirurides ne diffèrent pas de la microfilaire, mis à part une taille plus grande qui rend les structures plus nettes.

Chez toutes ces larves, la mobilité est assurée par les myofibrilles des cellules du revêtement ectodermique.

L'éclosion de ces larves à un stade embryonnaire nous paraît être un phénomène adaptatif très remarquable qui permet aux adultes d'émettre un nombre considérable de larves, car la suite de l'embryogénèse s'effectuera chez l'Arthropode vecteur. 


\section{Bibliographie}

ABE (S.), 1937. - Development of Wuchereria bancrofti in the mosquito, Culex quinquefasciatus. J. Med. Ass. Formosa, 36, 483-519 (en japonais, résumé en anglais).

ANDerson (R. C.), 1957. - Observations on the cycles of Diplotriaenoides translucidus Anderson and members of the genus Diplotriaena. Canad. J. Zool., 35, 14-24.

-, 1962. - On the development, morphology and experimental transmission of Diplotriaena bargusinica (Filarioidea: Diplotriaenidae). Canad. J. Zool., 40, 1175-1186.

BaIN (O.), 1969 a. - Morphologie des stades larvaires d'Onchocerca volvulus chez Simulium damnosum et redescription de la microfilaire. Ann. Parasitol., 44, 69-82.

- $1969 \mathrm{~b}$. - Etude morphologique du développement larvaire de Foleyella furcata chez Anopheles stephensi. Ann. Parasitol., 44, 165-172.

—, 1969 c. - Développement larvaire de Saurositus agamae hamoni n. s. sp., Eufilariinae parasite d'Agame en Haute-Volta, chez Anopheles stephensi. Ann. Parasitol., 44, 581-594.

-, 1970 a. - Etude morphologique du développement larvaire de Foleyella candezei chez Anopheles stephensi et Aedes aegypti. Ann. Parasitol., 45, 21-30.

-, 1970 b. - La cellule $\mathrm{R}_{1}$ des microfilaires (Nematoda), initiale du mésenchyme. Ann. Parasitol., 45, 227-235.

-, 1970 c. - Morphologie larvaire de Setaria labiatopapillosa (Nematoda, Filarioidea) chez Aedes aegypti. Ann. Parasitol., 45, 431-439.

- et Vassiliades (G.), 1969. - Cycle évolutif d'un Dicheilonematinae, Serratospiculum tendo. Filaire parasite du Faucon. Ann. Parasitol., 44, 595-604.

Chabaud (A. G.), 1954. - Sur le cycle évolutif des Spirurides et des Nématodes ayant une biologie comparable. Valeur systématique des caractères biologiques. Ann. Parasitol., 29, 42-88, 206-249, 358-425.

Coutelen (F.), 1929. - Nature et rôle biologique du corps central interne des microfilaires. Ann. Parasitol., 7, 410-418.

Feng (L. G.), 1936. - The development of microfilaria malayi in A. hyrcanus var. sinensis Wied. Chinese Med. J., suppl. 1, 345-367.

Fülleborn (F.), 1913. - Beiträge zur Morphologie und Differentialdiagnose der Mikrofilarien. Archiv f. Schiffs. Tropenhyg., 17, 7-72.

Golvan (Y.J.), 1957. - Les principales techniques de coloration des microfilaires sanguicoles. Bull. Soc. Path. exot., 50, 143-157.

Kobayashi (H.), 1940. - On the development of Microfilaria bancrofti in the body of the mosquito (Culex fatigans). Acta Jap. Med. trop., 2, 63-88.

KozeK (W. J.), 1968. - Unusual cilia in the microfilaria of Dirofilaria immitis. J. Parasitol., 54, 838-844.

Laurence (B. R.) et Simpson (M. G.), 1968. - Cephalic and pharyngeal structures in microfilariae revealed by staining. J. Helm., 42, 309-330.

- - , 1971. - The microfilaria of Brugia: a first-stage nematode larva. J. Helminth., $45,23-40$. 
Martini (E.) in Grasse (P.-P.), 1965. - Traité de Zoologie. Némathelminthes, Edit. Masson et $C^{10}$, Paris, 4, 731 pp.

NeLson (G.S.), 1962. - Observations on the development of Setaria labiatopapillosa using new techniques for infecting Aedes aegypti with this nematode. J. Helm., 36, 281-296.

-, 1963. - Dipetalonema dracunculoides (Cobbold, 1870) from the dog in Kenya; with a note on its development in the louse, Hippobosca longipennis. J. Helminth., $37,235-240$.

Nigon (V.) in Grassé (P.-P.), 1965. - Développement et reproduction des Nématodes. Traité de Zoologie. Némathelminthes, Edit. Masson et $C^{10}$, Paris, 4, $731 \mathrm{pp}$.

Quentin (J.-C.), 1969 a. - Cycle biologique de Pterygodermatites desportesi (Chabaud et Rousselot, 1956), Nematoda, Rictulariidae. Ann. Parasitol., 44, 47-58.

—, 1969 b. - Cycle biologique de Protospirura muricola Gedoelst, 1916 (Nematoda Spiruridae). Ann. Parasitol., 44, 485-504.

-, 1970. - Cycle biologique de Rictularia proni, Seurat, 1915, Nematoda Rictulariidae. Ontogénèse des structures céphaliques. Ann. Parasitol., 45, 89-103.

-, sous presse. - Présence de Spirura guyanensis chez les Marsupiaux néotropicaux. Cycle évolutif. Ann. Parasitol.

Rodenwalt (E.), 1908. - Die Verteilung der Mikrofilarien im Körper und die Ursachen des Turnus bei Microfilaria nocturna und diurna. Studien zur Morphologie der Mikrofilarien. Archiv f. Schiffs- u. Tropenhyg., 12, 5-30.

Roubaud (E.) et Descazeaux (J.), 1921. - Contribution à l'histoire de la mouche domestique comme agent vecteur des habronemoses d'Equidés. Cycle évolutif et parasitisme de l'Habronema megastoma (Rudolphi, 1819) chez la mouche. Bull. Soc. Path. exot., 14, 471-506.

STEWARD (J.S.), 1937. - The occurrence of Onchocerca gutturosa in cattle in England, with an account of its life history and development in Simulium ornatum Mg. Parasitol., 29, 212-219.

TAYLOR (A. E. R.), 1960. - Studies on the microfilaria of Loa loa, Wuchereria bancrofti, Brugia malayi, Dirofilaria immitis, D. repens and D. aethiops. J. Helm., 34, 13-26. 